\title{
Social Robots in Special Education: A Systematic Review
}

\author{
George A. Papakostas ${ }^{1} * \mathbb{0}$, George K. Sidiropoulos ${ }^{1}$, Cristina I. Papadopoulou ${ }^{1}$, Eleni Vrochidou ${ }^{1}$, \\ Vassilis G. Kaburlasos ${ }^{1}{ }^{(0}$, Maria T. Papadopoulou ${ }^{2}{ }^{(\mathbb{B}}$, Vasiliki Holeva ${ }^{3}{ }^{\mathbb{D}}$, Vasiliki-Aliki Nikopoulou ${ }^{3}$ \\ and Nikolaos Dalivigkas ${ }^{4}$
}

1 HUMAIN-Lab, Department of Computer Science, International Hellenic University, 65404 Kavala, Greece; georsidi@cs.ihu.gr (G.K.S.); mysapad@cs.ihu.gr (C.I.P.); evrochid@cs.ihu.gr (E.V.); vgkabs@cs.ihu.gr (V.G.K.)

2 4th Department of Pediatrics, Papageorgiou General Hospital, Aristotle University of Thessaloniki, 56403 Thessaloniki, Greece; mtpapado@gmail.com

3 1st Psychiatric Clinic, Papageorgiou General Hospital, Aristotle University of Thessaloniki, 56403 Thessaloniki, Greece; vholeva@yahoo.gr (V.H.); v.a.nikopoulou@gmail.com (V.-A.N.)

4 Euroaction, 54655 Thessaloniki, Greece; dalivigkas@gmail.com

* Correspondence: gpapak@cs.ihu.gr; Tel.: +30-2510-462-321

check for

updates

Citation: Papakostas, G.A.; Sidiropoulos, G.K.; Papadopoulou, C.I.; Vrochidou, E.; Kaburlasos, V.G.; Papadopoulou, M.T.; Holeva, V.; Nikopoulou, V.-A.; Dalivigkas, N. Social Robots in Special Education: A Systematic Review. Electronics 2021, 10, 1398. https://doi.org/10.3390/ electronics10121398

Academic Editor: Dah-Jye Lee

Received: 4 May 2021

Accepted: 7 June 2021

Published: 10 June 2021

Publisher's Note: MDPI stays neutral with regard to jurisdictional claims in published maps and institutional affiliations.

\section{Copyright: (c) 2021 by the authors.} Licensee MDPI, Basel, Switzerland. This article is an open access article distributed under the terms and conditions of the Creative Commons Attribution (CC BY) license (https:// creativecommons.org/licenses/by/ $4.0 /)$.

\begin{abstract}
In recent years, social robots have become part of a variety of human activities, especially in applications involving children, e.g., entertainment, education, companionship. The interest of this work lies in the interaction of social robots with children in the field of special education. This paper seeks to present a systematic review of the use of robots in special education, with the ultimate goal of highlighting the degree of integration of robots in this field worldwide. This work aims to explore the technologies of robots that are applied according to the impairment type of children. The study showed a large number of attempts to apply social robots to the special education of children with various impairments, especially in recent years, as well as a wide variety of social robots from the market involved in such activities. The main conclusion of this work is the finding that the specific field of application of social robots is at the first development step; however, it is expected to be of great concern to the research community in the coming years.
\end{abstract}

Keywords: social robots; child-robot interaction; special education; robot-assisted learning; systematic review

\section{Introduction}

There is no doubt that in recent years we have witnessed the Fourth Industrial Revolution, the so-called Industry 4.0 [1] in Europe and Society 5.0 [2] in Japan. Among the main features of this technological advancement is the use of artificial intelligence algorithms in processing the available large volume of data and making decisions from it. The role of robotic systems appears to be enhanced in the field of executing specific actions based on the derived decisions.

In this context, there is a growing trend in the application of robots outside of industrial workplaces, in people's daily lives, through the development of the so-called cyber-physical systems. As a direct consequence of this high integration of robots into society, the term social robots has been adopted [3] to include the new generation of robotic systems that interact with humans in daily activities such as entertainment [4-6], healthcare $[7,8]$, and education. An outstanding work about the social acceptance of robots in different application fields is presented systematically in [9].

The field of application of social robots in the education of children is of paramount interest for the following important reasons: (1) the education of the young people in each country is a critical factor for maintaining and promoting the culture and traditions of each nation and (2) the provision of specialized education services to children with various impairments contributes to their integration into the society with equal opportunities and 
rights by fighting the social exclusions. Additionally, in the particular conditions that humanity is experiencing, such as the current pandemic of COVID-19, the need for distance education of special categories of children can be met to a satisfactory degree with the use of social robots [10].

In recent years, several approaches have been proposed for the use of social robots in the education of adults, with the robot participating in the educational process with multiple roles, as a presenter, teaching assistant, teacher, peer, or tutor [11]. Recent studies have highlighted the great acceptance of social robots by children and their parents [12,13]. Children are very willing to interact with social robots for the following reasons: (1) children treat robots not just as simple machines but as cute toys; (2) robots gain children's attention because of their childlike appearance, while they have many interactive abilities (movements, sounds, colored lights, etc.); (3) social robots have the patience to teach children through many repetitions without getting tired; and (4) social robots are emotionally and behaviorally stable during their interaction with children.

The aforementioned advantages of using social robots in the educational process are much more valuable when the children interacting with the robots have some impairment. In these cases, the educational process is adapted to the special requirements of the children, with social robots being the center of attention for children. For example, in the case of children with autism, a critical factor in the effectiveness of an educational process is the children's engagement in the lesson, as they present several difficulties in concentrating their attention. In this regard, several attempts to study the degree of children's engagement during the lesson, as well as to develop ways to attract children's attention in social robots, have been presented $[14,15]$. To this end, several multimodal behavioral analysis methods have been proposed [16,17]. Summarizing, the study of the methodologies applying social robots in special education is of particular interest, as it includes several scientific and technological challenges for various scientific disciplines, e.g., child psychology, developmental psychology, cognitive science, neuroscience, computer science.

\subsection{Related Work}

In order to better identify the contribution of this work to the research field of social robots for educational purposes, it will be constructive to present and comment on similar works that have been proposed so far.

The first systematic review of the application of social robots in education was presented in 2013 by Mubin et al. [18]. This review presented the published approaches based on the following four criteria: (1) the field of educational activity, (2) the role of the robot in the educational process, (3) the type of robot, and (4) the way the robot behaves. Following this categorization of publications and without mentioning any specific methodology for mining the included studies, about 60 papers published from 1996 to the beginning of 2013 were examined.

The second systematic literature review was presented in 2018 by Belpaeme et al. [11]. This study focused on identifying the technological challenges that exist in the development of robots for education, as well as the role of the appearance and behavior of robots in the outcomes of the educational procedure. For the analysis of the literature, three main criteria were adopted: (1) the effectiveness of the application of social robots in education, (2) the impact of integrating social robots into education and (3) the different roles that a social robot can play in the educational process. In light of the above criteria, about 80 papers published by 2018 were studied.

The third bibliographic study that investigates in a systematic way the application of social robots in education was presented in 2019 by Ismail et al. [19]. In this publication, for the first time in the literature, a thorough analysis and review of the application of social robots in the education of children with autism were presented. The study identified significant gaps in the international literature on the application of social robots to the education of children with autism. The identified gaps were (1) the lack of high diversity in the objectives of the researches, (2) the bias of the researches concerning the environment 
and the applied methodology in relation to the expected behaviors of children with autism and (3) the long-term effectiveness of interventions. The study analyzed about 130 papers published by 2018 and constitutes by far the most complete analysis of the use of social robots in educating children with autism.

\subsection{Contribution of This Study}

From the analysis of the previous section, it is concluded that most review publications regarding the application of social robots in education are limited to researches on typical education and only one review is dedicated to the case of children with ASD. The research field of integrating social robots into typical education is characterized by many scientific and technological challenges. However, the use of social robots in special education involves additional challenges, as the behavior and skills of children who may have one or multiple impairments vary.

The research community has identified and raised significant awareness of these challenges in special education, with the result that a significant number of efforts have been made in recent years. Although few [20], with limited scope, and non-systematic works have been published that review the application of social robots in special education, the gap for a systematic bibliographic review of this field still exists from the literature. This work seeks to fill this gap by identifying, organizing, processing, and creatively presenting research proposals for the use of social robots in special education in a holistic way.

The high importance of the application of robots in special education, both for children and for society, along with the lack of a systematic study in this field were the main pillars of inspiration for the present work. In addition to the systematic presentation of the research in this field, this paper seeks to contribute in the direction of answering specific questions formulated as follows:

\section{A. Question 1-What is the degree of integration of social robots in special education?}

This question is answered through a quantitative and statistical analysis of the research attempts published in recent years. For this purpose, Section 2 presents in detail the research activity by presenting specific quantitative measures.

\section{B. Question 2-In which impairments have the social robots been used, under what conditions and experimental settings and with what results?}

This question is answered in Section 3 through a structured presentation of the qualitative and quantitative characteristics of the research protocols that have been carried out, with a simultaneous reference to their technical settings.

\section{Question 3-What types of social robots are appropriate for each impairment and what is their performance?}

In Section 4, a detailed analysis of the used robots and their performance for each impairment is presented as an attempt to answer this question. Conclusions about the appropriateness of the used social robots are drawn, towards defining a user guide for future research.

D. Question 4-What are the challenges that need to be addressed by the researchers in this field, in order to achieve the successful integration of social robots in special education?

The information presented in the first four sections stimulates a constructive discussion in Section 5, in the direction of defining the main challenges provided by the researchers or concluded by this study.

Finally, Section 6 concludes this study by summarizing the answers to the above questions and puts forward the next actions that need to be planned for promoting social robots in special education to the next readiness level. 


\section{Materials and Methods}

The methodology followed in this systematic review is based on the principles proposed by Kitchenham [21]. The proposed method consists of three main phases: planning, conducting, and reporting the review. Khalid [22] suggested preparing a checklist for conducting a systematic review, which was followed in the present systematic review. Some of the items in the checklist that are also used herein are: (1) the sources that were searched and the search terms used, (2) the inclusion/exclusion criteria and (3) the data extraction procedure.

\subsection{Sources and Search Terms}

The search was conducted in the Scopus [23] abstract and citation database, which provides a large amount of peer-reviewed literature from different fields. The search rules incorporating specific terms that were used in this study were the following:

(1) “(human-robot interaction) AND ((special education) OR (special needs education) OR disorder)" and

(2) "human-robot interaction" AND "autism".

It should be noted that in both cases the search rules were applied to the article title, abstract and keywords. Both search rules overlap each other to a certain degree. The first case, though, searches for cases where a human-robot interaction was applied in any of the cases of special education or special needs education or generally a disorder. The second case searches for cases where a human-robot interaction was applied only on cases with autism.

\subsection{Inclusion and Exclusion Criteria}

The studies that were found needed to include at least two of the search terms that were used during the search. This means that one such study should certainly include the use of a robot and the target group should have at least one kind of impairment so that the group is considered to have special needs. Moreover, an additional constraint was applied; the studies should have been conducted between 2008 and 2020, meaning that the survey focused on the studies conducted in the last 13 years. This constraint is applied in order to analyze the recent status and trends. A diagram showing the exclusion procedure is shown in Figure 1, according to which 99 papers were further processed after removing duplicates and less relevant records by checking their titles and abstracts.

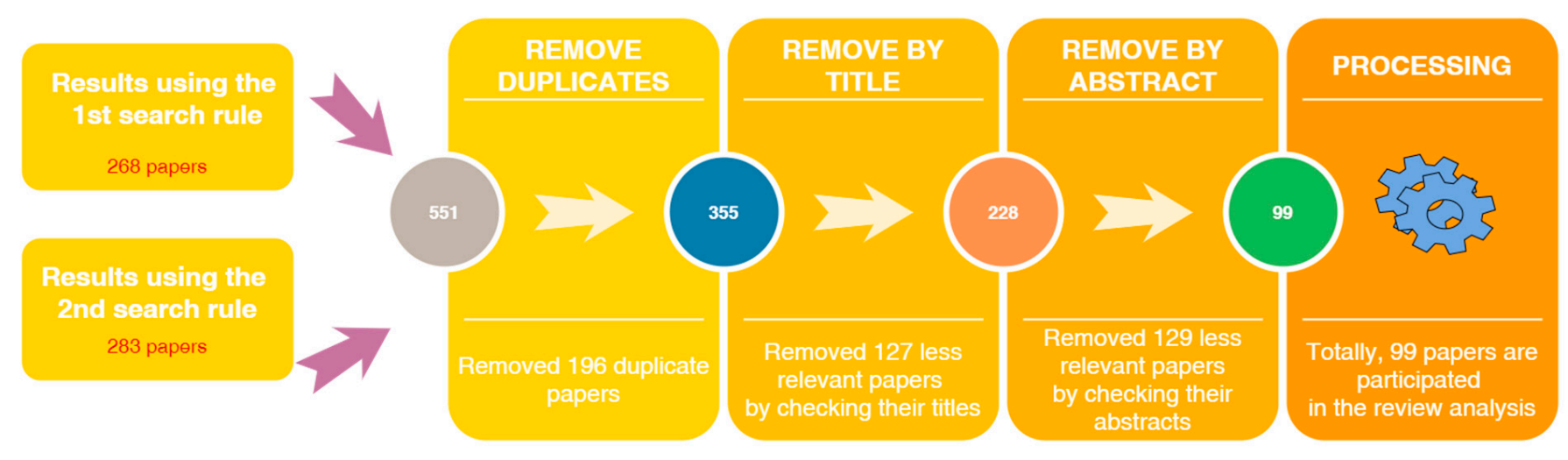

Figure 1. Source selection procedure.

\subsection{Data Extraction}

The data that were extracted from each study were the following:

- The impairment type of the target group.

- The age range of the target group. 
- The role of the robot in the interaction (if the interaction occurred only with the robot or with the cooperation of other persons, namely an instructor, other children, or a family member).

- The type of interaction between the target group and the robot (game, interaction, lessons, or other).

- The name of the robot that was used.

- $\quad$ The type of robot (humanoid, non-humanoid).

- The challenges faced during the study from the aspect of the functionality of the robot. The above data were extracted from each study and organized into an Excel file.

\subsection{Statistical Results}

With the application of the aforementioned methodology, a sufficient set of published research papers were collected in the context of this work. The statistical analysis of all published publications is presented in this section.

\subsubsection{Demographics}

Figure 2 shows that most of the studies are conducted in Europe $(47 \%, \mathrm{~N}=46)$, followed by Asia $(29 \%, \mathrm{~N}=29)$ and North America $(16 \%, \mathrm{~N}=16)$. The rest $(8 \%, \mathrm{~N}=8)$ of the studies were conducted in South America, Oceania, while some studies included children from multiple continents.

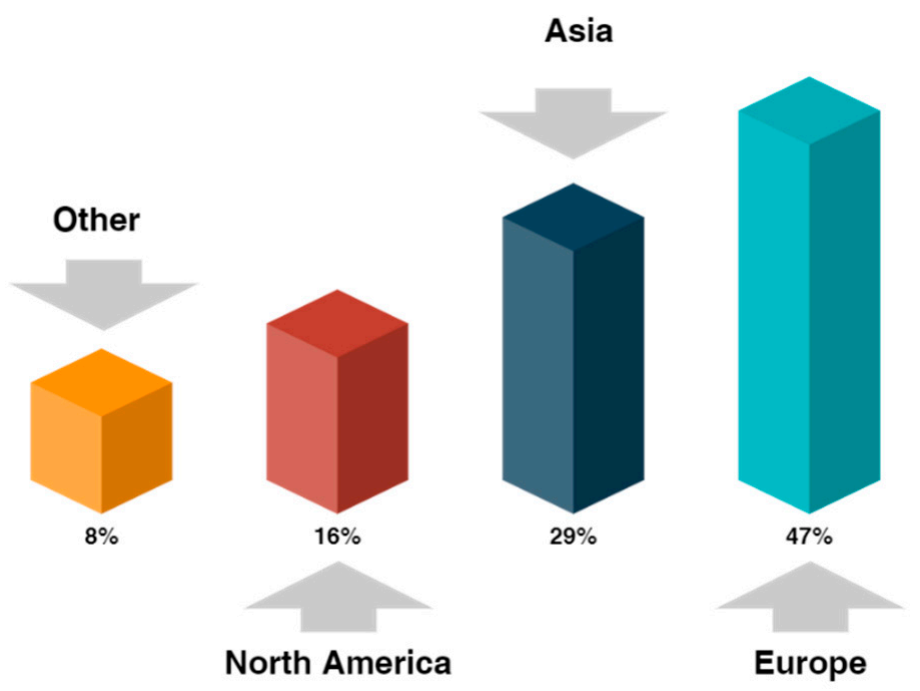

Figure 2. Percentage of studies per continent.

The detailed country map of the conducted studies is illustrated in Figure 3. Most studies were conducted in the U.S.A. $(14 \%, \mathrm{~N}=14)$, followed by the UK $(12 \%, \mathrm{~N}=12)$, Italy $(8 \%, N=8)$, Malaysia $(6 \%, N=6), \operatorname{Iran}(5 \%, N=5)$ and Romania $(5 \%, N=5)$. The countries in which the studies were conducted are very sparse, with $50 \%(\mathrm{~N}=49)$ of all corresponding to the following 28 countries: China (4), Portugal (4), France (4), Japan (4), Korea (3), Saudi Arabia (1), Qatar (2), Pakistan (2), New Zealand (2), the Netherlands (2), Australia (2), Greece (2), Belgium (2), the International Consortium (2), Kazakhstan (1), Azerbaijan (1), Turkey (1), Skopje (1), Singapore (1), Brazil (1), Quebec (1), Canada (1), Colombia (1), Ecuador (1), Finland (1), Ukraine (1), and Luxemburg (1).

\subsubsection{Timeline}

Figure 4 shows the number of publications per year. It seems that 2018 and 2019 were the years with the most publications $(\mathrm{N}=16)$, followed by 2016 with 14 publications. It is worth mentioning that the last year (2020) of this study reveals a very low research activity, mainly due to the pandemic conditions caused by COVID-19. 


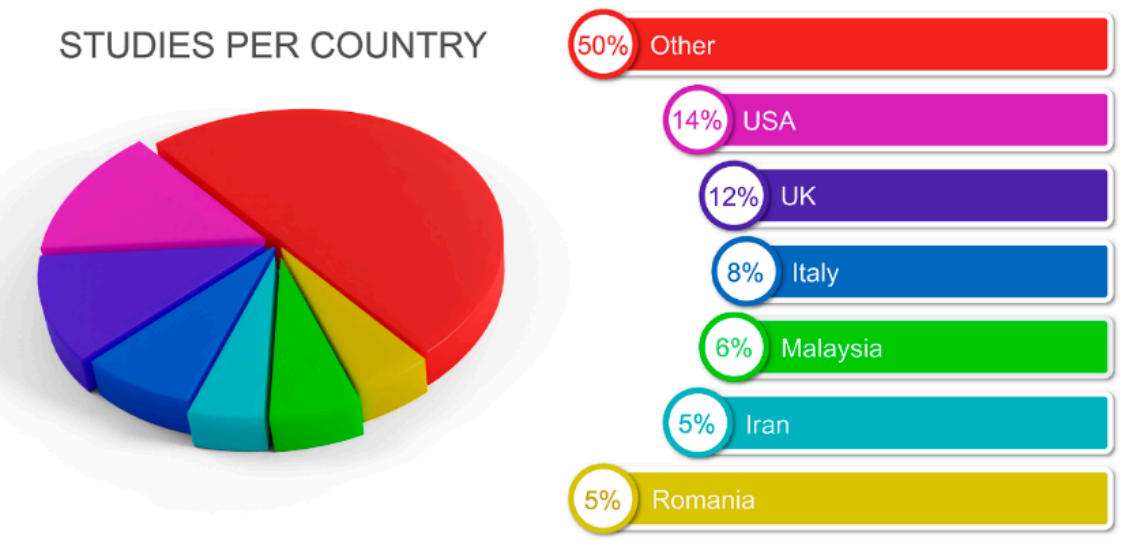

Figure 3. Percentage of studies per country.

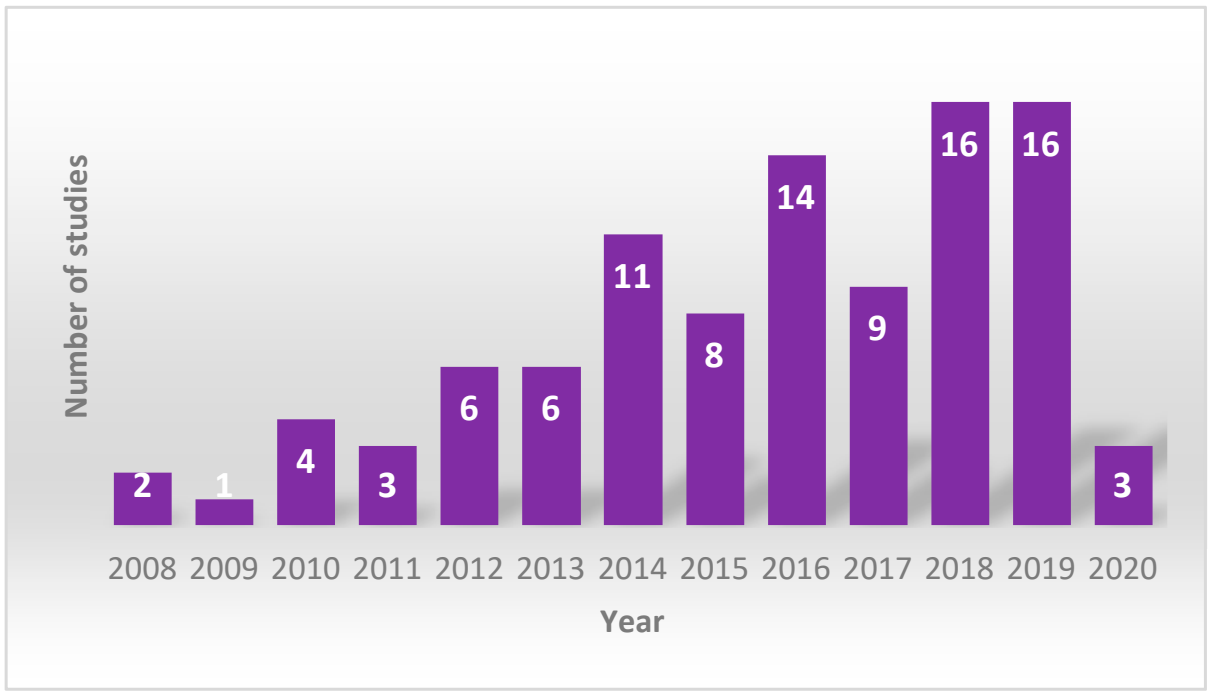

Figure 4. Publications per year.

The above publications are divided into publications for conferences, journals and books, as shown in Figure 5. Furthermore, there is an additional category showing that a study was conducted in the context of a dissertation.

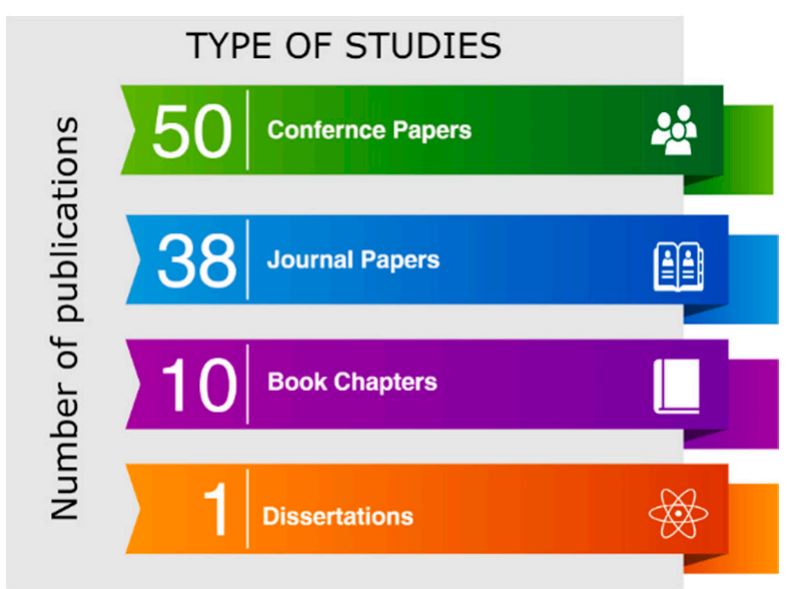

Figure 5. Number of publications per publication type. 


\subsubsection{Impairments}

The variety of impairments for which the social robots have been applied is very large. Figure 6 illustrates that most of the studies were conducted with children with autism spectrum disorder (ASD), as, according to CDC's Autism and Developmental Disabilities Monitoring Network [24], it is a very common disorder among children in the past years (1 in 59 children).

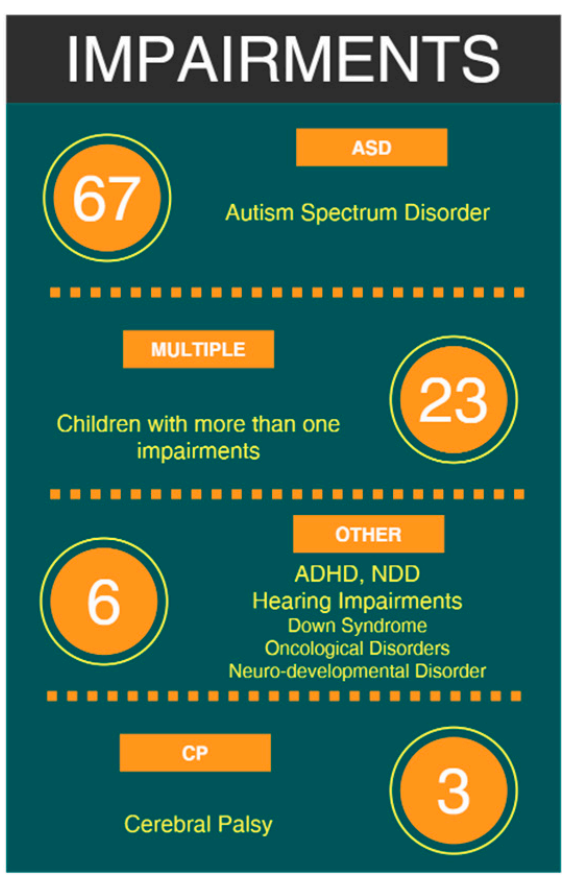

Figure 6. Number of applications of robots on different kind of impairments.

Following this impairment, most cases included children with cerebral palsy-CP (3). The applications of social robots in cases of cerebral palsy are training-oriented interactions. These interactions focus on training the child's movements through training and other activities. Some of those cases also use a ball kicking interaction as a training method.

It should be noted here that the cases named "multiple" are cases where the participating children in the studies had multiple impairments. In addition to that, there were studies where the target group had a variety of disabilities, for example, two children with ASD and two children with Down Syndrome.

It seems that the different impairments on which social robots were applied are quite sparse: intellectual disabilities, down syndrome, developmental disorder, attention deficit hyperactive disorder (ADHD), psychosis, Prader-Willi syndrome, oncological disorders, learning disabilities, joint attention impairments, physical disabilities, spinal muscular atrophy, Asperger, amentia, hearing impairments, neuro-developmental disorder (NDD), etc.

\section{Impairments Taxonomy}

In this section, an attempt to constructively discuss the findings of the literature analysis of the published studies, based on the type of impairments of the children participating in the research, is presented. Moreover, Tables 1-4 summarize the main quantitative characteristics of the examined studies of each impairment category.

\subsection{Autism Spectrum Disorder (ASD)}

Children with autism spectrum disorder impairment constitute the bigger target group for delivering social robot-aided special education. According to the literature analysis presented in the previous section, 66 studies focused on children with ASD, aiming to improve the social skills, attention, etc. of the children. The high percentage of the studies 
belonging to this category shows that ASD seems to be a priority in these types of studies. In 2019, Ismail et al. [19] presented a thorough study in deploying social robots for educating children with ASD. For this reason, it was decided to discuss herein only the approaches proposed in 2019 and 2020, since the works published before 2019 have been analyzed in-depth in the outstanding review of Ismail et al. [19].

Taheri et al. [25] aimed to improve the children's social skills by teaching them music with the NAO robot. In the context of music-based scenarios, four children, at the age of six years old, interacted with the robot and learned to play drum and xylophone. The study showed several different results derived from questionnaires answered by both parents and therapists, having significant improvements on the children, such as: positively affecting their walking, speaking and handwriting, autism severity and parental stress decreased, social skills increased and improvement of the stereotyped behaviors. Those results though are limited due to the small number of participants and having no control group and the results can be highly affected by classes taken by children outside the study.

A study that was part of the EC-FP7 funded DREAM project [26] developed a system to make the NAO robot autonomous in therapy, in order to improve the children's joint attention, imitation and turn-taking skills. They divided the experiments into two phases, one with a teleoperated robot (11 children, three to five years old) and one with the autonomous system (27 children), conducting experiments with a single-case alternative treatment design. The children took part in six to eight game sessions, with both groups showing signs of improvement within a significant time effect.

Study [27] also followed a simple approach, by teleoperating the CommU robot to provide daily-life guidance to the individuals and aimed to explore if caregivers can better address concerns of adolescents via the robot. The two participating girls (15 and 18 years old) were simply communicating with the robot, in the presence of the therapist, disclosing problems with human relationships or the identity of an individual they disliked, behaviors that had not previously occurred in direct conversations with teachers in their daily lives.

Attention is another highly affected aspect by ASD, which many studies have tried to improve through robotic interventions. Joint activities are a common interaction setup in this case, as they are a common interaction to elicit the children's attention through various ways, through specific tasks therapies. Quite a few studies have used the NAO robot in these types of interactions; for example, the study in [28] incorporated two NAO robots to introduce the concept of multi-person communication to the children, testing cases with inter-robot communication and without. They validated the effectiveness of the intervention by analyzing the children's cognitive state of the brain before and after the interventions. Twelve children (11 males and one female) participated in the study between the ages of 3.7 to 10.4 years old, which managed to improve their multi-communication skills. Specifically, the Childhood Autism Rating Scale showed the effectiveness of the therapy, with statistical results for joint attention and EEG module with $F$ value $=20.36, p$-value $=1.74 \times 10^{-6}$ and $F$ critical value $=3.28$; joint attention and imitation were $F$ value $=23.93, p$-value $=3.79 \times 10^{-7}$ and $F$ critical value $=3.28$ and the eye contact duration of each participant improved over the experiments. Another study that carried out a joint attention therapy was presented in [29], which aimed to find the effect of different visual stimuli in order to improve the children's joint attention, by measuring the total eye contact time and number of times for each visual cue. The study included 12 children (11 males and one female), aged between 3.5 and 7.2 years old. Two attention cues were examined, with one them being more effective (blinking or rasta), with the blinking having $32.4 \mathrm{~s}$ and $65.1 \%$ accuracy eye contact and rasta having $38.8 \mathrm{~s}$ with $80.3 \%$. The results showed that the prominence of the cue is important in establishing eye contact, showing effectiveness in the improvement of joint attention.

The INSIDE system, which allows for complex, semi-unstructured interactions and assessed the autonomy of the proposed system in the context of therapy sessions with children, was proposed by Melo et al. [30]. They used the non-humanoid social robot ASTRO, in therapy sessions with the children. The study was executed with three different 
groups of children (five boys 3.9 to 5.9 years old, six children and 18 children) targeting different scientific goals. The study with the last group of children included four weeks of interventions and 121 total sessions. All participants managed to complete more than $50 \%$ of the tasks during the intervention, with times being lower when the completion rate was higher. The eye gaze percentages showed that high percentages did not necessarily correspond to desirable behaviors and, lastly, most of their speech was directed to the robot, showing high engagement with the robot.

Ishak et al. [31] developed a new framework for robot and human interaction. They selected the humanoid social robot Rero, due to its reconfigurable capability, its ability to be developed in many forms, mobility, speech, its ability to be controlled and programmed and its attractiveness. The nine boys that participated, aged five to six years old, participated in introductory, listening and following instructions, looking and naming objects, focusing and learning colors and focusing and matching colors interaction modules. From the questionnaires that were answered, three out of five modules obtained high scores, with module 4 having the highest score.

Wood et al. [32] were developed some interaction games, to be played with the robot Kaspar to improve the children's Visual Perspective Taking and Theory of Mind. The study was divided into an initial proof of concept that included three children, ages from three to five years old, and then a pilot study with 12 children (five female and seven males), aged from 11 to 14 years old. The sessions included the Smarties test, Sally-Anne test and the Charlie test, showing no significant differences between the pre- and post-test assessments. They utilized the McNemar test to analyze the results, with the Smarties test having $p>0.05$, Sally-Anne $p>0.05$ and the Wilcoxon signed ranks for the Charlie test $(\mathrm{z}=-1.41, p>0.05)$. Despite those results, 7 out of 12 children achieved a higher success level in at least one post-test, with seven children showing an increased number of successful tasks in the post-test.

Sign language teaching has also been studied in [33], by designing a humanoid social robot InMoov by taking into account the characteristics of children with ASD (impaired language, communication, social behavior and narrow flexibility in daily activities). The robot taught nine assistive signs to 10 children, who managed to imitate the robot and keep their focus on it, reporting positive experiences, with a one-sample Wilcoxon signed rank test revealing that the median number of total successful repetitions was significantly greater than zero $(p=0.011)$.

The impact of a robot through storytelling, games, exercises and singing interactions with the children was tested and analyzed by Qidwai et al. [34]. The NAO robot that was used in the study, with the teacher being present, showing improved performance with the children. Fifteen children participated in the study, aged from 7 to 11 years old. The improvement was quantified in terms of the robot activity as an independent variable, following dependent behavioral variables from the responses of the children, specifically: the number of trials, activity response time, response type and behavior retention. Applying the null hypothesis, showing that it was too significant and could be disqualified through the experiments, meant that the use of NAO showed significant improvement in several aspects and confirmed the confidence level for the techniques used.

Study [35] was part of an ongoing project and included the NAO robot and a pet-like robot MiRo, in interaction with play activities within a simulated clinical procedure. Five five-year-old children took part in the study, with which parents and carers were present during the interactions to ensure that they were comfortable. From the video analysis they conducted, along with the parents' feedback, they confirmed that there were possible benefits to reducing the children's anxiety and increased their compliance with instructions. Specifically, four out of five children enjoyed the interaction with both robots, executing on average $82 \%$ of the robot's instructions, while one engaged with only $17 \%$ of those. The same four children completed the procedures and were happy to stay longer.

Zhang et al. [36] investigated the ability of children with ASD to develop social skills through playing distrust and deception games with the NAO social robot. Two equally 
sized groups of children participated in this study: twenty children (two females, 18 males) with ASD and ages between five and eight years old and twenty (three females, 17 males) typical developing children. All the children participated in three main tasks, namely the "warm-up session", "distrust and deception, and "interview" about their anthropomorphic thinking of the robot. An important outcome of this study was the observation that children with ASD seemed to more readily consider the robot anthropomorphic than the children with TD. Moreover, children with ASD liked to interact with a robot more than with a human in distrust tasks.

Some useful quantitative information of the studies discussed in this section is summarized in Table 1. It is noted that the symbol "-- implies that this information is not provided in the corresponding reference.

Table 1. Quantitative information of the examined ASD studies.

\begin{tabular}{|c|c|c|c|c|c|c|c|}
\hline Ref. & Objectives & Interaction & $\begin{array}{l}\text { Age Range } \\
\text { (Years) }\end{array}$ & $\begin{array}{l}\text { Participants Total } \\
\text { (Female, Male) }\end{array}$ & $\begin{array}{l}\text { Robot } \\
\text { Name }\end{array}$ & $\begin{array}{l}\text { Robot } \\
\text { Type }\end{array}$ & $\begin{array}{l}\text { Robot } \\
\text { Role }\end{array}$ \\
\hline [25] & $\begin{array}{l}\text { Teach fundamentals of } \\
\text { music, improve } \\
\text { social/cognitive skills }\end{array}$ & $\begin{array}{l}\text { Music-based } \\
\text { scenario }\end{array}$ & 6 & $4(0,4)$ & NAO & Humanoid & Main interaction \\
\hline [26] & $\begin{array}{l}\text { Improve joint attention, } \\
\text { imitation and } \\
\text { turn-taking skills }\end{array}$ & Games & $\begin{array}{c}3-5 \\
\text { (Phase 1) } \\
- \\
\text { (Phase 2) }\end{array}$ & $\begin{array}{c}11(-,-) \\
(\text { Phase 1) } \\
27(-,-) \\
\text { (Phase 2) }\end{array}$ & $\mathrm{NAO}$ & Humanoid & $\begin{array}{l}\text { Main interaction. } \\
\text { Therapist present }\end{array}$ \\
\hline [27] & $\begin{array}{l}\text { If caregivers can better } \\
\text { address concerns of } \\
\text { adolescents with ASD via } \\
\text { a desktop } \\
\text { humanoid robot }\end{array}$ & Conversations & 15,18 & $2(0,2)$ & CommU & Humanoid & $\begin{array}{l}\text { Main interaction, } \\
\text { tele-operated by } \\
\text { caregiver, cases of } \\
\text { caregiver being in the } \\
\text { same room and in a } \\
\text { different room }\end{array}$ \\
\hline [28] & $\begin{array}{l}\text { Find parameters that can } \\
\text { improve the } \\
\text { multi-communication skills }\end{array}$ & $\begin{array}{l}\text { Intervention } \\
\text { adaptive therapy } \\
\text { games (joint } \\
\text { attention } \\
\text { and imitation) }\end{array}$ & $3.7-10.4$ & $12(1,11)$ & $2 \mathrm{NAO}$ & Humanoid & Main interaction \\
\hline [29] & $\begin{array}{l}\text { Find effect of different } \\
\text { visual stimuli in order to } \\
\text { improve the } \\
\text { joint attention }\end{array}$ & $\begin{array}{l}\text { Joint attention } \\
\text { therapy }\end{array}$ & $3.5-7.2$ & $12(1,11)$ & NAO & Humanoid & Main interaction \\
\hline [30] & Assess autonomy of robot & Therapy sessions & $\begin{array}{c}3.9-5.9 \\
- \\
-\end{array}$ & $\begin{array}{c}5(0,5) \\
6(-,-) \\
18(-,-)\end{array}$ & ASTRO & $\begin{array}{l}\text { Non- } \\
\text { Humanoid }\end{array}$ & Main interaction \\
\hline [31] & $\begin{array}{l}\text { Measure effectiveness of } \\
\text { interaction module }\end{array}$ & $\begin{array}{l}\text { Interaction } \\
\text { modules }\end{array}$ & $5-6$ & $9(0,9)$ & Rero & Humanoid & $\begin{array}{l}\text { Main interaction, } \\
\text { therapist present, } \\
\text { experimenter hidden }\end{array}$ \\
\hline [32] & $\begin{array}{l}\text { See whether the games } \\
\text { played with the robot } \\
\text { improve the children's } \\
\text { visual perspective taking } \\
\text { (VPT) and theory of } \\
\text { mind (TOM) }\end{array}$ & Games & $\begin{array}{c}3-5 \\
\text { (initial } \\
\text { proof of } \\
\text { concept), } \\
11-14 \\
\text { (pilot study) }\end{array}$ & $\begin{array}{c}3(-,-) \\
12(5,7)\end{array}$ & Kaspar & Humanoid & $\begin{array}{l}\text { Main interaction, } \\
\text { therapist present }\end{array}$ \\
\hline [33] & $\begin{array}{l}\text { Examine whether children } \\
\text { successfully imitate the } \\
\text { robot and if they focus } \\
\text { attention on the robot }\end{array}$ & $\begin{array}{l}\text { Sign language } \\
\text { teaching }\end{array}$ & - & $10(-,-)$ & InMoov & Humanoid & $\begin{array}{l}\text { Main interaction, } \\
\text { therapist and } \\
\text { companions present }\end{array}$ \\
\hline [34] & $\begin{array}{c}\text { Test and analyze impact } \\
\text { of robot }\end{array}$ & $\begin{array}{l}\text { Storytelling, games, } \\
\text { exercises, song }\end{array}$ & $7-11$ & $15(-,-)$ & NAO & Humanoid & $\begin{array}{l}\text { Main interaction, } \\
\text { teacher present }\end{array}$ \\
\hline [35] & $\begin{array}{l}\text { Evaluate benefits in } \\
\text { anxiety reduction and } \\
\text { instruction compliance }\end{array}$ & $\begin{array}{l}\text { Mixed play } \\
\text { activities }\end{array}$ & 5 & $5(-,-)$ & $\begin{array}{l}\text { NAO, } \\
\text { MiRo }\end{array}$ & $\begin{array}{l}\text { Humanoid, } \\
\text { Non- } \\
\text { Humanoid }\end{array}$ & $\begin{array}{l}\text { Main interaction, } \\
\text { therapist and } \\
\text { parents present }\end{array}$ \\
\hline [36] & Develop social skills & $\begin{array}{c}\text { Distrust and } \\
\text { deception games }\end{array}$ & $5-8$ & $20(2,18)$ & $\mathrm{NAO}$ & Humanoid & Main interaction \\
\hline
\end{tabular}




\subsection{Multiple Impairments}

Table 2 shows the information for each study that included children with multiple impairments (children that had more than one impairment). These studies seem to have several differences in the kind of interactions, the target of improvement and the type of robot that was used. This is reasonable, as these cases seem to be more complex as the impairment is not strictly defined, meaning that each child has more than one impairment and the "group" of impairments being different from child to child and from study to study.

In detail, some of the disabilities that the children had in these studies include ASD, motor and language impairments, tuberous sclerosis, Down syndrome, ADHD, cognitive impairments, cerebral palsy, epilepsy and intellectual disabilities.

That being said, the aims of those studies can be grouped as follows: investigation of the effects of the robot, improvement of cognitive skills and mobility, improvement of mobility, improvement of communication and interaction skills, improvement of communication and learning a specific skill. One can see that some of those aims have similarities; for example, one study may aim to improve just the cognitive skills of the robot while another will aim to improve the children's cognitive skills along with its mobility. The aims of those studies were achieved with a different kind of interaction. Those interactions were exercises for the specific aim (speech exercises for speech therapy, movement exercises for mobility therapy, etc.), games and play sessions with the robot, free interactions and communication and interaction with the robot. It is obvious that the studies that aim to improve specific skills do so using the same kind of interaction.

Following that, the different robots that were used in those studies are NAO, Iromec, Kaspar, SPELTRA, Paro, and in two cases, a Lego robot (WeDo and Lego Mindstorms). Most of those robots are humanoid (NAO, Kaspar, SPELTRA and Lego Mindstorms) and it seems that they are closely related to the improvement of the social skills and mobility of the children. This is because those robots can carry out movements that children can imitate and, as a result, improve their mobility. In the case of non-humanoid robots (Iromec, Paro and WeDo), they are connected with the improvements of the children's cognitive skills as in those cases the interaction is a game/play session or a free interaction.

More specifically, Lindsay and Hounsell [37] helped to address the educational, cognitive, physical and social needs of the children, engaging youth with disabilities in a robotics program; as a result, the children enjoyed and learned about computer programming and building robots, while also considering working in this area in the future. Children with spinal muscular atrophy, cerebral palsy, developmental disorder, and intellectual disabilities participated in this study. They aimed to engage the children in STEM by performing workshops with other engineers and teachers in which the children had to program the robot to solve problems.

In this kind of study, the type of the robot does not seem to be an important factor as the children's main aim was to program the robots so that they can solve problems. This is because the children did not have direct interaction with the robot (for example, playing a game or social interaction) and so the robot did not need to have human-like characteristics. The robots that were used in the study were WeDo [38] and Lego Mindstorms [38], which, although one is humanoid, have quite a few differences in appearance compared to other social robots.

During the study, the children had to build the robots in addition to programming them, with the help of teachers and other staff members of the hospital in which the study was conducted. The 18 children that participated in the workshops were between the ages of six and 13 years old, four of which were female and 14 male. Concerning the weaknesses of the study, the first one is that it was a pilot study and was conducted at only one site. Secondly, girls were under-represented in the program, and therefore, they recommended that future studies make concerted efforts to include more girls. Thirdly, they recognized that STEM learning for children with various disabilities may have different meanings and is an area worthy of further exploration. 
In [39], the results obtained in the experimental plan shown that children with cerebral palsy and communication disorders can adapt quickly to the robot, and in the case of the phonemic area, an immediate improvement in the results has been demonstrated. In [40], it was stated that the children with global cognitive retardation, developmental disorder, epilepsy, and language retardation were interested in the robot and in the play activity, regardless of their different disabilities, and they were engaged in the activity from the very beginning of the session. The robot's appearance and behavior did not seem to evoke an agent with its inner states intentionality and this radically reduces the potential of the robot as a mediator of social exchanges. The main issues are mainly related to the functional aspect of the visual interface that does not adequately support a life-like metaphor and meaning attribution processes. Another problem was related to the design of the physical appearance of the robot: children perceived the two screen displays (one used for the face and the other one located on top of the main body) as separate components that do not constitute a whole. Most of the child's attention was focused on the body screen where the commands of the game are entered. The face disappears in the background as well as most of the robot expressiveness. This negatively impacted the interpretation process, thus forbidding the emergence of the role of social mediator.

Three studies focusing on attention, imitation, joint attention and turn-taking were presented in [41]. One subject's "no response" count decreased and flattened out with a noticeable improvement in a future session. Likewise, the "correct response" count consistently increased with a noticeable improvement at a later session. These counts are consistent with the increase of total directives over time. For another subject, the results were inconclusive, although they performed well during the first session (total directives $=16$, no response $=1$, and correct response $=15$ ), were despondent during the second session and were turn-taking during the third session, and thus were removed from the therapy in both cases. Another subject made considerable progress according to the speech and language pathologist (SLP) and the special education teacher.

A study to identify the utility of interacting with the NAO robot was presented in [42], including six children with several impairments, e.g., ASD, global developmental delay, cerebral palsy, epilepsy. The Wilcoxon signed-rank test showed that for the group as a whole, ratings were significantly $(z=2.023, p=0.043)$ higher when working with the robot examining the individual results indicates that for three of the pupils (S.H., S.T. and T.H.) the engagement increased over time.

Marti and Iacono [43] investigated the utility of the Iromec robot to support the educational activities of four children by playing, concerning the following areas of development: sensory development (S), motor development (M), social and emotional development (SE), cognitive development (C) and communication and interaction (CI). They did not record any positive changes for the sensory developmental area, even if these data were not confirmed from the qualitative analysis and the comments of the special education teachers. The motor developmental area was the only one that did not report any negative changes. Overall, the unchanged items for all the children were 334, the decremented items were 128 and the incremented items were 120, with 144 items being recorded for two of the children and 147 for the other two.

The study in [44] included 11 children aged between 6 and 10 years old with different and multiple neuro-developmental disorders (ASD, Down syndrome, intellectual disabilities, Prader-Willi syndrome and psychosis). It aimed to investigate the potential of the robot as a tool to help children with NDD learn through free play. As some of the children had severe cognitive deficits and others had socialization problems, they were split into two groups in which the first group played alone with the robot and the second played with a peer. They used the non-humanoid robot Teo, which was co-designed by a team of designers, engineers and NDD therapists in the context of the study. This means that the choice of the robot may be critical in cases of children with different NDD disorders. In this case, Teo should be able to have multimodal interactions, offer different types of stimuli, provide clear feedback and have consistent behavior. 
During unforeseen situations, the trainer (therapist) had to assist the robot with problems it could not solve for the children by itself. In scenarios where the robot was teaching a child different skills or behaviors, they needed to reduce unforeseen situations to a minimum. The robot's speech, however, provoked multiple reactions. The children reacted verbally to the rate of the robot's speech and some inaccuracies in pronunciation were obviously noticed by the children, prompting critical remarks from the children.

The variables that were analyzed during this study were: communication with Teo, manipulation of Teo, externalization of need, positive emotions, negative emotions, creativity, body stereotypes and social play (for the case of children that were paired with the robot and a second peer). Overall, two children had the highest increase on the variable "communication with Teo" during the second session, while others had a high decrease. In addition, for four children, there was an increase in some variables from the first session to the second, while there was a strong decrease in two children. The variable "manipulation of Teo" had a decrease for all children except for two of them. Additionally, the variables "externalization of needs", "positive emotions" and "negative emotions" showed a positive trend in the second session in both groups of children. Lastly, the study mentions that in empirical researches involving subjects with severe and multiple disabilities, causality relationships are hard to measure and it is almost impossible to isolate all potentially confounding variables that may influence the improvement.

In [45], the two participating adolescents with ASD and mental impairment had resistances and challenges during the interaction with the robot initially, for example, not being able to distinguish the colored cards or not being able to activate the robot's motions. However, they had improvements in the interaction and understanding of the interaction and its tools, managing to activate its movements with cards or not, without problems. Additionally, the behaviors "ignores robot" and "stares at the robot" that were measured decreased throughout the sessions and the children became more engaged with the robot.

Children with physical disabilities (cerebral palsy or brain injury), and cognitive impairments, some of them unable to walk, participated in a study in [46]. For this reason, the interaction between the robot and the children was based on body exercises that focused on improving their movements and their cognitive skills, as most of them also had cognitive impairments. The humanoid robot used in this study was ZORA (NAO) due to its simplified software, which is focused on the application in the rehabilitation and care sector and due to its attractive appearance, variation of interaction and communication skills. This study included 17 participants, of which seven were female and 10 male, between the ages of 2.6 to 18 years old. The quantitative results of the study showed a positive contribution of the robot towards achieving therapeutic and educational goals as measured with the IPPA (individually prioritized problem assessment). Specifically, the mean score of IPPA before the sessions was 11.8, with a minimum of 6 and a maximum of 15 (SD: 3.0), and the mean score after the sessions was 8.8 , with a minimum of 3 and a maximum of 15.3 (SD: 3.5).

Iacono et al. [47] compared the Iromec and Kaspar social robots in interacting with 10 children with ASD and cognitive impairments. This study has shown positive results in the developmental target areas. Additionally, and according to the teachers' statements, the interaction with the robots seemed to have had a positive influence on individual development.

In another study [48], three students with ASD and intellectual disabilities became more confident and willing to engage in conversation after interacting with the NAO robot over a period of time. All of the students enrolled in the disability unit (DU) took the opportunity to interact with the robot. For some students, progress was more marked than for others, and the acquired skills were relative to the cognitive ability of the student. In the fourth study, the children were interested in the robot and in the play activity regardless of their different disabilities. Children were engaged in the activity from the very beginning of the session. 
Nakadoi [49] investigated the effectiveness of the Paro robot in the therapy of nine children with ASD, developmental disorders, mood disorder, anxiety disorder, etc. aged between 8 and 19 years old. The first patient seemed to treat Paro like a living animal. They saw a pleased expression on her face when some patients were interested in Paro and gathered around her and Paro. Two weeks later, though her autistic trait remained completely unchanged, she gradually started to talk in a relaxed way. For the second patient, they gave him Paro instead of an antipsychotic drug when he had the impulse to go back home. He liked Paro and held it with pleasure in the day room of the ward almost every day, though they could not find deep interaction between him and other patients. He often said hello to Paro. He seemed to treat Paro like a living animal. He sometimes went to sleep with Paro, which was an exceptional allowance for him. Two weeks later, they saw a calm expression on his face.

In [50], the 30 participating children with cognitive disabilities were interacting with the NAO robot towards improving their cleaning skills. They answer a pre-test and posttest questionnaire with six verb and picture questions to assess their improvement after the tests. All groups improved their knowledge and skills between the pre-test $(\mathrm{M}=5.43$, $\mathrm{SD}=1.85)$ and the post-test $(\mathrm{M}=7.05, \mathrm{SD}=1.60)$. The students' IQ levels showed an improvement in functional knowledge and skills at the end of this study. Although all groups' scores increased, students with moderate cognitive disabilities and severe cognitive disabilities achieved significantly better improvements than those with mild cognitive disabilities.

The authors in [51] focused on the impact of children with ASD and intellectual disabilities (ID) interacting with social robots. They applied the robot as an assisting tool for the Verbal Behavior Milestones Assessment and Placement Program (VB MAPP). The humanoid robot NAO was used due to its 25 degrees of freedom, face detection capabilities, its ability to mimic eye contact by moving its head accordingly, simulate emotions by changing its eye colors and because it can capture a lot of information about the environment. Only six males participated with a mean age of 8.7 years old.

The children with mild, moderate, and severe ID were successful at the end of the therapy; in fact, they were able to adequately perform the VB-MAPP tasks. On the other side, two children with profound ID did not benefit from the robot-assisted therapy, as they were not able to perform any task. The video analysis shows that all children increased the time spent imitating the robot. More significant is the progress of those that learned how to perform the task, while the increase of the two children that were not successful, at around $5 \%$, was negligible.

The results suggest that there is a need to find more advanced solutions and approaches for persons with profound ID. This is the case that requires more care and, thus, the robot-assisted therapy may be very welcome by the therapeutic team, who can reduce their workload by allowing parts of the treatment to be taken over by a robot. Due to the relatively low number of participants and the absence of a control group, the results of this study only indicate the underlying potential of research in this field.

Wan et al. [52] conducted a medium-scale study for investigating the preferences of 74 children with ASD and developmental delay (DD), for the appearances and functionalities of the robots interacting with them. The authors applied a visual attention analysis methodology, as well as a statistical analysis of questionnaires, in order to derive conclusions regarding the physical robot design and the ability of three different robots (Dabao, XiaoE, and Mika) to attract the attention of the children. Dabao robot was the most popular for the children and their parents, while the proposed attention analysis method was able to provide quantitative information w.r.t. the engagement level of the participating children.

In [53], the authors aimed to study the effect of the Cozmo robot on the behavior of six adults with ASD, intellectual disabilities and Down syndrome when they play with it in groups. This interaction with the robot had a positive effect on the development of collaborative and competitive attitudes between the participants. 
Zhanatkyzy et al. [54] analyzed the video recordings of several sessions in which 21 children (three female, 18 male) with ASD, ADHD and delayed speech development (DSD) interacted with a NAO robot during play. This study aimed to discover behavioral patterns of the children as well as to measure their engagement in the play. Due to the interaction with the robot, children showed an increasing engagement and eye contact with the robot session by session. The same authors in another study [55] proposed a novel robot behavior targeting children with ASD and ADHD, aiming to increase the engagement level of the 15 boys who participated in a series of sessions. The experimental results showed an increase in the level of engagement and therefore the improvement of the acceptance by the children of the educational process.

Table 2. Quantitative information of the examined studies with multiple impairments.

\begin{tabular}{|c|c|c|c|c|c|c|c|c|}
\hline Ref. & Impairments & Objectives & Interaction & $\begin{array}{l}\text { Age } \\
\text { Range } \\
\text { (Years) }\end{array}$ & $\begin{array}{c}\text { Participants } \\
\text { Total } \\
\text { (Female, Male) }\end{array}$ & $\begin{array}{l}\text { Robot } \\
\text { Name }\end{array}$ & $\begin{array}{l}\text { Robot } \\
\text { Type }\end{array}$ & $\begin{array}{l}\text { Robot } \\
\text { Role }\end{array}$ \\
\hline [37] & $\begin{array}{l}\text { Spinal muscular } \\
\text { atrophy, cerebral palsy, } \\
\text { developmental } \\
\text { disorder, } \\
\text { intellectual disabilities }\end{array}$ & $\begin{array}{l}\text { Engage children } \\
\text { in STEM }\end{array}$ & Workshops & $6-13$ & $18(4,14)$ & $\begin{array}{l}\text { WeDo, } \\
\text { Lego } \\
\text { Mind- } \\
\text { storms/EV3 }\end{array}$ & $\begin{array}{l}\text { Non- } \\
\text { Humanoid, } \\
\text { Hu- } \\
\text { manoid }\end{array}$ & Main interaction \\
\hline [39] & $\begin{array}{c}\text { Cerebral palsy, } \\
\text { communication disorders }\end{array}$ & Speech therapy & Exercises & - & $14(-,-)$ & SPELTRA & Humanoid & $\begin{array}{l}\text { Main interaction, } \\
\text { therapist present }\end{array}$ \\
\hline$[40]$ & $\begin{array}{l}\text { Global cognitive } \\
\text { retardation, } \\
\text { developmental } \\
\text { disorder, epilepsy, } \\
\text { language retardation }\end{array}$ & $\begin{array}{l}\text { Investigation of } \\
\text { effects of robot }\end{array}$ & Game & $6-11$ & $5(3,2)$ & Iromec & $\begin{array}{l}\text { Non- } \\
\text { Humanoid }\end{array}$ & $\begin{array}{l}\text { Main interaction, } \\
\text { single and two } \\
\text { child tests, one } \\
\text { teacher involved in } \\
\text { activity, } \\
\text { another observing }\end{array}$ \\
\hline [41] & $\begin{array}{c}\text { ASD, speech- } \\
\text { language impairment, }\end{array}$ & $\begin{array}{l}\text { Improve social } \\
\text { and } \\
\text { attentions skills }\end{array}$ & $\begin{array}{l}\text { Social in- } \\
\text { teraction } \\
\text { and } \\
\text { exercises }\end{array}$ & $6-9$ & $3(1,2)$ & NAO & Humanoid & $\begin{array}{l}\text { Main interaction, } \\
\text { parent and } \\
\text { researcher present, } \\
\text { robot operated }\end{array}$ \\
\hline [42] & $\begin{array}{c}\text { ASD, Global } \\
\text { developmental delay, } \\
\text { cerebral palsy, epilepsy }\end{array}$ & $\begin{array}{l}\text { Improve } \\
\text { mobility }\end{array}$ & Sessions & $9-17$ & $6(2,4)$ & NAO & Humanoid & Main interaction \\
\hline [43] & $\begin{array}{l}\text { Global cognitive } \\
\text { disability, tuberous } \\
\text { sclerosis, ADHD, } \\
\text { motor impairments }\end{array}$ & $\begin{array}{c}\text { Improve } \\
\text { mobility and } \\
\text { cognitive skills }\end{array}$ & $\begin{array}{l}\text { Play } \\
\text { sessions }\end{array}$ & $6-11$ & $4(3,1)$ & Iromec & $\begin{array}{l}\text { Non- } \\
\text { Humanoid }\end{array}$ & $\begin{array}{l}\text { Main interaction, } \\
\text { individual or } \\
\text { group sessions, } \\
\text { teacher and } \\
\text { facilitator present }\end{array}$ \\
\hline$[44]$ & $\begin{array}{l}\text { Prader-Willi disorder, } \\
\text { psychosis, Down } \\
\text { syndrome, } \\
\text { intellectual disabilities }\end{array}$ & $\begin{array}{l}\text { Learn through } \\
\text { play with the } \\
\text { robot } \\
\text { Investigation of } \\
\text { effects of robot }\end{array}$ & Free play & $6-10$ & $11(-,-)$ & Teo & $\begin{array}{l}\text { Non- } \\
\text { Humanoid }\end{array}$ & $\begin{array}{l}\text { Main interaction, } \\
\text { therapist present }\end{array}$ \\
\hline [45] & $\begin{array}{c}\text { ASD, } \\
\text { mental impairment }\end{array}$ & $\begin{array}{l}\text { Improve } \\
\text { mobility }\end{array}$ & $\begin{array}{l}\text { Play } \\
\text { sessions }\end{array}$ & adolescents & $2(-,-)$ & $\begin{array}{l}\text { Lego } \\
\text { Mind- } \\
\text { storms } \\
\text { NTX }\end{array}$ & Humanoid & $\begin{array}{l}\text { Main interaction, } \\
\text { researcher present }\end{array}$ \\
\hline [46] & $\begin{array}{l}\text { Physical disabilities, } \\
\text { cognitive impairments }\end{array}$ & $\begin{array}{l}\text { Improvement of } \\
\text { movements and } \\
\text { cognitive skills }\end{array}$ & $\begin{array}{l}\text { Body } \\
\text { exercises }\end{array}$ & $2.6-18$ & $17(7,10)$ & $\begin{array}{l}\text { ZORA } \\
(\mathrm{NAO})\end{array}$ & Humanoid & $\begin{array}{l}\text { Main interaction, } \\
\text { Wizard of } \mathrm{Oz}\end{array}$ \\
\hline [47] & $\begin{array}{c}\text { ASD, } \\
\text { cognitive impairments }\end{array}$ & $\begin{array}{l}\text { Improve social } \\
\text { and } \\
\text { cognitive skills }\end{array}$ & $\begin{array}{c}\text { Play } \\
\text { scenarios }\end{array}$ & $8.3 \mathrm{avg}$. & $10(1,9)$ & $\begin{array}{l}\text { Iromec, } \\
\text { Kaspar }\end{array}$ & $\begin{array}{l}\text { Non- } \\
\text { Humanoid, } \\
\text { Hu- } \\
\text { manoid }\end{array}$ & $\begin{array}{l}\text { Main interaction, } \\
\text { experimenter } \\
\text { present }\end{array}$ \\
\hline [48] & $\begin{array}{c}\text { ASD, } \\
\text { intellectual disabilities }\end{array}$ & $\begin{array}{l}\text { Improve } \\
\text { communication } \\
\text { skills }\end{array}$ & $\begin{array}{l}\text { Comm- } \\
\text { unication } \\
\text { and } \\
\text { interaction. }\end{array}$ & $8-13$ & $3(0,3)$ & $\mathrm{NAO}$ & Humanoid & Main interaction \\
\hline
\end{tabular}


Table 2. Cont.

\begin{tabular}{|c|c|c|c|c|c|c|c|c|}
\hline Ref. & Impairments & Objectives & Interaction & $\begin{array}{l}\text { Age } \\
\text { Range } \\
\text { (Years) }\end{array}$ & $\begin{array}{c}\text { Participants } \\
\text { Total } \\
\text { (Female, Male) }\end{array}$ & $\begin{array}{l}\text { Robot } \\
\text { Name }\end{array}$ & $\begin{array}{l}\text { Robot } \\
\text { Type }\end{array}$ & $\begin{array}{l}\text { Robot } \\
\text { Role }\end{array}$ \\
\hline [49] & $\begin{array}{c}\text { ASD, developmental } \\
\text { disorders, } \\
\text { mood disorder, } \\
\text { anxiety disorder }\end{array}$ & $\begin{array}{l}\text { Investigation of } \\
\text { effects of robot }\end{array}$ & $\begin{array}{l}\text { Free inter- } \\
\text { action }\end{array}$ & $8-19$ & $9(5,4)$ & Paro & $\begin{array}{l}\text { Non- } \\
\text { Humanoid }\end{array}$ & Main interaction \\
\hline [50] & $\begin{array}{c}\text { Different levels of } \\
\text { cognitive disabilities }\end{array}$ & $\begin{array}{l}\text { Learn cleaning } \\
\text { skills }\end{array}$ & $\begin{array}{l}\text { Training } \\
\text { session }\end{array}$ & $10-18$ & $30(-,-)$ & NAO & Humanoid & $\begin{array}{l}\text { Main interaction, } \\
\text { controlled by } \\
\text { experimenter }\end{array}$ \\
\hline [51] & $\begin{array}{c}\text { ASD, } \\
\text { intellectual disability }\end{array}$ & Rehabilitation & $\begin{array}{l}\text { Imitation } \\
\text { tasks }\end{array}$ & 8.7 avg. & $6(0,6)$ & NAO & Humanoid & $\begin{array}{c}\text { Main interaction, } \\
\text { teacher present }\end{array}$ \\
\hline [52] & $\begin{array}{l}\text { ASD, developmental } \\
\text { delay (DD) }\end{array}$ & $\begin{array}{l}\text { Find the } \\
\text { preferences of } \\
\text { the children for } \\
\text { appearances } \\
\text { and } \\
\text { functionalities } \\
\text { of the robots }\end{array}$ & Free play & 7.8 avg. & $74(11,63)$ & $\begin{array}{l}\text { Dabao } \\
\text { XiaoE } \\
\text { Mika }\end{array}$ & Humanoid & Main interaction \\
\hline [53] & $\begin{array}{l}\text { ASD, intellectual } \\
\text { disability, } \\
\text { Down syndrome }\end{array}$ & $\begin{array}{l}\text { Analyze the } \\
\text { behavior of the } \\
\text { participants }\end{array}$ & Games & $24-42$ & $6(5,1)$ & Cozmo & $\begin{array}{l}\text { Non- } \\
\text { Humanoid }\end{array}$ & Main interaction \\
\hline [54] & $\begin{array}{l}\text { ASD, ADHD, delayed } \\
\text { speech } \\
\text { development (DSD) }\end{array}$ & $\begin{array}{c}\text { Engagement } \\
\text { level measuring, } \\
\text { find behavioral } \\
\text { patterns }\end{array}$ & Games & $4-8$ & $21(3,18)$ & $\mathrm{NAO}$ & Humanoid & $\begin{array}{l}\text { Main interaction, } \\
\text { researcher } \\
\text { is present }\end{array}$ \\
\hline [55] & ASD, ADHD & $\begin{array}{l}\text { Apply a novel } \\
\text { robot behavior }\end{array}$ & $\begin{array}{l}\text { Imitation } \\
\text { games }\end{array}$ & $\begin{array}{c}3-5 \\
6-12\end{array}$ & $\begin{array}{l}7(0,7) \\
8(0,8)\end{array}$ & $\mathrm{NAO}$ & Humanoid & $\begin{array}{l}\text { Main interaction, } \\
\text { researcher } \\
\text { is present }\end{array}$ \\
\hline
\end{tabular}

\subsection{Cerebral Palsy}

This section summarizes (Table 3) the studies that included children with cerebral palsy or focused on treating or improving the mobility of children with cerebral palsy.

The studies in $[56,57]$ focused on improving the children's mobility, both by performing body exercises with the robot (for example, performing specific movements, kicking a ball, or sitting and standing). Study [56] included six participants aged between four and nine years old, while in [57] only two male children participated, ages 9 and 13 years old. The experiments in [56] were executed using KineTron robot, and [57,58] with NAO. KineTron was chosen because of its ability to carry out precise movements with specified speed and force, providing feedback about position and tension and the ability to arrange complex movement patterns with the use of its special software RoboPlus. NAO was chosen for the same reasons as it includes position sensors at each joint, loudspeakers, sonars on the body, voice recognition and bumpers on its feet.

On the other hand, Ríos-Rincón et al. [59] focused on improving the children's playfulness by letting them play with the Lego Invention "Roverbot" robot [38]. This nonhumanoid robot was selected mainly because, as mentioned above, they aimed to improve the children's playfulness and not their mobility or motor skills. This study included one female and three male participants between the ages of five and nine years old. The playfulness of the children was scored based on Rasch analysis using Facets. All of the data points in the intervention phase fell above the extended celeration line demonstrating, according to Bloom's criterion, which change during the intervention was statistically significant ( $p$-value $<0.05)$. The effect size, calculated using the improvement rate difference (IRD), was moderate: $0.58(58 \%)$ for one child and large: $1(100 \%)$ for the other children. During intervention, all children had an increase in Control-self specifically the items decides, modifies, initiates and transitions. The fit statistics of the playfulness data indicated that $87 \%$ of the data was within acceptable limits of the Rasch model. Additionally, mothers' rating of play performance and satisfaction with performance on the COPM increased for 
all children during the intervention and some carry-over effects were perceived by mothers after the intervention. Most (81\%) COPM scores improved more than two units during the intervention.

The usage of Lego Invention robots in [59] had many advantages, although they are not $100 \%$ accurate in their movements. Some children were momentarily disappointed when the robot did not go in the exact expected direction, similar to previous research. Children expressed frustration when the infrared signal did not reach the robot sensor in some sessions. A robot wheel and the robot scoop fell off in some sessions. Moreover, the authors mentioned that the robot seemed to misinterpret children with speech impairments.

Table 3. Quantitative information of the examined studies with cerebral palsy.

\begin{tabular}{cccccccc}
\hline Ref. & Objectives & Interaction & $\begin{array}{c}\text { Age Range } \\
\text { (Years) }\end{array}$ & $\begin{array}{c}\text { Participants Total } \\
\text { (Female, Male) }\end{array}$ & $\begin{array}{c}\text { Robot } \\
\text { Name }\end{array}$ & $\begin{array}{c}\text { Robot } \\
\text { Type }\end{array}$ & $\begin{array}{c}\text { Robot } \\
\text { Role }\end{array}$ \\
\hline$[56]$ & $\begin{array}{c}\text { Neurophysiological } \\
\text { rehabilitation }\end{array}$ & Exercises & $4-9$ & $6(-,-)$ & KineTron & Humanoid & $\begin{array}{c}\text { Main interaction, } \\
\text { therapist present }\end{array}$ \\
\hline$[57]$ & Improve mobility & Exercises & $9-13$ & $2(0,2)$ & NAO & Humanoid & Main interaction \\
\hline & $\begin{array}{c}\text { Improve } \\
\text { playfulness }\end{array}$ & $\begin{array}{c}\text { Training } \\
\text { sessions }\end{array}$ & $5-9$ & $4(1,3)$ & $\begin{array}{c}\text { Lego } \\
\text { Invention } \\
\text { "Roverbot" }\end{array}$ & $\begin{array}{c}\text { Non- Humanoid } \\
\text { Main interaction, } \\
\text { child with mother }\end{array}$ \\
\hline
\end{tabular}

\subsection{Other Impairments}

Table 4 shows the information for each study that is not categorized to the previous discussed cases. Moreover, these studies are discussed hereafter.

\subsubsection{Attention Deficit Hyperactivity Disorder (ADHD)}

A single study [60] was conducted with children with only ADHD and it seems that it was carried out to observe the effects of the interaction of children with the robot. The study focused on collaborative learning (learn about the history of Japan) with the robot while the teachers that were present observed the interaction. Ifbot [61], which was used in this study, is a non-humanoid robot. The design of the robot is itself conversational, which can be used to support learning and promotes effective learning, with a limited number of expressions and arm and body movements. Additionally, the robot was controlled with the Wizard of $\mathrm{Oz}$ method during the interaction by one of the teachers. Three children participated, which is a small sample size and without any reference to their age and gender. Lastly, the results of the interaction were evaluated by the total time of the interaction in each case (with and without the robot), for two different learning sessions. Specifically, the learning time (min:sec) without the robot was 15:28 and 12:49 for each session and with the robot was 18:05 and 13:45, the running time (number of times the children get up and run) without the robot was 6 and 5 and with the robot was 7 and 9, and the average break time (min:sec) during the sessions without the robot was 0:49 and 1:52 and with the robot was $0: 37$ and 1:18.

\subsubsection{Hearing Impairments}

The conducted search in the literature found only one study that focused on children with hearing impairments. This study [62] focused on teaching the children sign language through two different sign games. In this game, after learning the signs from a multiplechoice test at two different levels (beginner and advanced), the children could choose one of the available robots (Robovie R3 [63] and Nao) to play with. Those two robots were chosen due to their degrees of freedom ( 29 and 25 , respectively) and their fingers in their hands (five and three, respectively). The participating children were 31 in total (16 female and 15 male) and aged between seven and 16 years old. Ten of those children were advanced sign users and the others were beginner level sign users. 
As a result, children of different levels of hearing impairment and sign language information were motivated to play with the applications. The children of beginner level preferred to play with the NAO robot first (12 children played their first game with NAO and nine with R3). However, their average error rates were smaller in the games played with R3 than NAO in the first games (average error rate with $\mathrm{R} 3=2.8 ; \mathrm{NAO}=4.7$ ), and total error in both games $(\mathrm{R} 3=3.1 ; \mathrm{NAO}=4.3)$. Lastly, there was a case of a signed word ("table") where the children noted that the robots, mostly in the case of NAO, did not correctly sign it because R3 has more distinguishable hands and fingers.

\subsubsection{Down Syndrome}

Two studies that included children with Down syndrome were found in the literature $[64,65]$. None of the studies seem to have specific therapeutic aims for the children, although there may have been some positive results from those interactions. The studies focused on comparing the robots they used or investigated their effects on the children. In both cases, the interactions between the robot and the children included play scenarios with specific objectives or a free play scenario where the children were left to play freely with the robot.

The NAO robot and Lego Mindstorm KRAZ3 (humanoid and non-humanoid, respectively) were deployed in [64]. The two robots were used for two weeks for eight sessions each. Generally, during the tasks, the children were asked to move the robots in different ways (buttons or verbally) in particular directions, inside a maze, or in other kinds of conditions. NAO was chosen because it can be programmed to pick out specific inputs and respond appropriately, it can change its posture from standing down to standing up, can dance, talk and respond to sounds and pictures, and simple questions can be asked to it either verbally or with a tablet. On the other hand, the Lego Mindstorm was chosen because it can be controlled to move in different directions, detect colors, and be controlled with an infrared remote and generally because it was designed for educational purposes. Study [65] was similar to the first study, where they compared a humanoid (Kaspar [66]) and non-humanoid (Iromec [67]) robot through play scenarios. The scenarios that the children played were: "turn-taking", "move the robot" and an imitation scenario. Iromec robot was used because it can move in space, detect obstacles, has a digital touch screen on top of it with graphical interface elements, can engage in different play scenarios and can be configured in different ways and equipped with extra features. Kaspar was used because its size is similar to that of a child (as its torso and legs were taken from a child-sized shop mannequin), it can execute different play behaviors, can express simple and complex emotions and can be controlled remotely or operated semi-autonomously. The number of participants in both studies was low. In [64], one female and three males were included between the ages of 10 and 16 years old, and in [65], there was only one eight-year-old girl.

As far as the results are concerned, ref. [64] showed that three out of four participants had a higher percentage engagement with the Lego Mindstorm robot than with the NAO robot. In the fourth participant, there was no difference in percentage engagement between the two robots. In terms of percentage errors, there was no difference between the two robots in all four participants. Means for the percentage of engagement for each participant were: (1) NAO: 93.52, Lego: 96.12; (2) NAO: 94.11, Lego: 94.59; (3) NAO: 90.71, Lego: 95.45; and (4) NAO: 79.66, Lego: 91.50. The means for the percentage of error for each participant were: (1) NAO: 17.02, Lego: 20.25; (2) NAO: 25.60, Lego: 14.69; (3) NAO: 13.69, Lego: 19.23; and (4) NAO: 13.78, Lego: 12.29. For [65], the results seem to indicate that the child was more interactive with the experimenter and the robot during the sessions with Kaspar, since in most behavioral categories the rates per minute were higher while playing with Kaspar. The only behavioral category that showed a significant difference in favor of the Iromec platform was "touching the robot".

Lastly, for study [64], a limited range of learning objectives was also included; although the humanoid NAO robot is capable of a wide variety of functions when compared to the non-humanoid Lego Mindstorm, learning objectives were limited to those that could be 
carried out with both robots. There was also a difference between the two robots in the way they were controlled. The NAO robot was controlled using the tablet, whilst the Lego Mindstorm robot had its own remote control. Pupils found it easier to use the tablet than the remote control.

\subsubsection{Oncological Disorders}

During the search, one case [68] that included children with oncological disorders (acute myeloid leukemia, relapsed acute lymphoblastic leukemia, brain tumor, T-cell lymphoma, etc.) was found. The study aimed to increase the motivation of the children in participating in exercises. It is well-known that it is very difficult to motivate children with oncological disorders, and for this reason, gross motor exercises were carried out with and without a human/robot and with and without music.

The robot that was used was ZORA [69], which is a NAO robot launched and programmed by the Belgian company QBMT. ZORA was used because it already had dances preprogrammed by QBMT and was able to insert other sets of exercises or music through the 'composer' function that was available.

The number of participating children was 14, aging between three and 15 years old, with five being female and nine male. As mentioned above, they had varying oncological disorders, from leukemia to brain tumors.

Although children with oncological disorders are not motivated, the application of the robot, with the combination of music, for dance exercises had positive outcomes. The motivation of the children was assessed using three measures based on the Fun Toolkit (Smileyometer, Again score and Fun Sorter). From the results, it seems that having a humanoid robot instructor to deliver and help with the physical activity program (instead of a human) appeared to increase the children's initial motivation to participate.

\subsubsection{Neuro-Developmental Disorder (NDD)}

In a single study [70], the increase of the engagement of 11 participants aged between 25 and 42 years old, in a storytelling intervention scenario with the ELE pet-like robot, was investigated. The results were encouraging since $80 \%$ of the participants scored higher in the sessions, revealing that the ELE non-humanoid robot was able to engage more with all the subjects than a human speaker. It is worth noting that the ELE robot was able to attract the attention of the adults, although it is very cheap and with low interaction capabilities of the social robot.

Table 4. Quantitative information of the examined studies with miscellaneous impairments.

\begin{tabular}{|c|c|c|c|c|c|c|c|c|}
\hline Ref. & Impairment & Objectives & Interaction & $\begin{array}{c}\text { Age } \\
\text { Range } \\
\text { (Years) }\end{array}$ & $\begin{array}{c}\text { Participants } \\
\text { Total } \\
\text { (Female, Male) }\end{array}$ & $\begin{array}{l}\text { Robot } \\
\text { Name }\end{array}$ & $\begin{array}{l}\text { Robot } \\
\text { Type }\end{array}$ & $\begin{array}{l}\text { Robot } \\
\text { Role }\end{array}$ \\
\hline [60] & ADHD & $\begin{array}{l}\text { Observe effects of } \\
\text { the interaction }\end{array}$ & $\begin{array}{l}\text { Collaborative } \\
\text { learning }\end{array}$ & - & $3(-,-)$ & Ifbot & $\begin{array}{l}\text { Non- } \\
\text { Humanoid }\end{array}$ & $\begin{array}{l}\text { Wizard of } \mathrm{Oz}, \\
\text { main } \\
\text { interaction }\end{array}$ \\
\hline [62] & $\begin{array}{l}\text { Hearing im- } \\
\text { pairments }\end{array}$ & $\begin{array}{c}\text { Sign } \\
\text { language teaching }\end{array}$ & Sign game & $7-16$ & $27(16,11)$ & $\begin{array}{c}\text { Robovie R3, } \\
\text { NAO }\end{array}$ & Humanoid & $\begin{array}{c}\text { Main } \\
\text { interaction }\end{array}$ \\
\hline [64] & $\begin{array}{c}\text { Down } \\
\text { syndrome }\end{array}$ & $\begin{array}{l}\text { Compare the } \\
\text { two robots }\end{array}$ & $\begin{array}{c}\text { Play } \\
\text { scenarios }\end{array}$ & $10-16$ & $4(1,3)$ & $\begin{array}{l}\text { NAO, Lego } \\
\text { Mindstorms } \\
\text { KRAZ3 }\end{array}$ & $\begin{array}{l}\text { Humanoid, } \\
\text { Non- } \\
\text { Humanoid }\end{array}$ & $\begin{array}{l}\text { Support the } \\
\text { learning }\end{array}$ \\
\hline [65] & $\begin{array}{l}\text { Down } \\
\text { syndrome }\end{array}$ & $\begin{array}{c}\text { Investigate effects } \\
\text { of robots }\end{array}$ & $\begin{array}{c}\text { Play } \\
\text { scenarios }\end{array}$ & 8 & $1(1,0)$ & $\begin{array}{l}\text { Iromec, } \\
\text { Kaspar }\end{array}$ & $\begin{array}{l}\text { Non- } \\
\text { Humanoid, } \\
\text { humanoid }\end{array}$ & $\begin{array}{c}\text { Main } \\
\text { interaction, } \\
\text { experimenter } \\
\text { interacting }\end{array}$ \\
\hline
\end{tabular}


Table 4. Cont.

\begin{tabular}{|c|c|c|c|c|c|c|c|c|}
\hline Ref. & Impairment & Objectives & Interaction & $\begin{array}{c}\text { Age } \\
\text { Range } \\
\text { (Years) }\end{array}$ & $\begin{array}{c}\text { Participants } \\
\text { Total } \\
\text { (Female, Male) }\end{array}$ & $\begin{array}{l}\text { Robot } \\
\text { Name }\end{array}$ & $\begin{array}{l}\text { Robot } \\
\text { Type }\end{array}$ & $\begin{array}{l}\text { Robot } \\
\text { Role }\end{array}$ \\
\hline [68] & $\begin{array}{c}\text { Oncological } \\
\text { disorders }\end{array}$ & $\begin{array}{l}\text { Increase } \\
\text { motivation of } \\
\text { children to } \\
\text { perform exercises }\end{array}$ & $\begin{array}{c}\text { Gross } \\
\text { motor } \\
\text { exercises }\end{array}$ & $3-15$ & $14(5,9)$ & $\begin{array}{l}\text { ZORA } \\
(\mathrm{NAO})\end{array}$ & Humanoid & $\begin{array}{c}\text { Main } \\
\text { interaction }\end{array}$ \\
\hline [70] & NDD & $\begin{array}{c}\text { Increase } \\
\text { engagement }\end{array}$ & Storytelling & $25-42$ & $11(-,-)$ & ELE & $\begin{array}{c}\text { Non- } \\
\text { Humanoid }\end{array}$ & $\begin{array}{c}\text { Main } \\
\text { interaction }\end{array}$ \\
\hline
\end{tabular}

\subsection{Challenges}

Based on the material presented in the previous sections, it is concluded that there is a strong effort to implement social robots in each category of impairment. The main research outcomes as well as the new challenges that emerged from these researches are summarized in Table 5.

Table 5. Main reported outcomes and challenges of some of the examined studies.

\begin{tabular}{|c|c|c|c|}
\hline Reference & Impairment & Outcomes & Challenges \\
\hline [25] & ASD & $\begin{array}{l}\text { Sessions positively affected their walking, } \\
\text { speaking and handwriting; autism severity } \\
\text { and parental stress decreased, social skills } \\
\text { increased and stereotyped } \\
\text { behaviors improved. }\end{array}$ & $\begin{array}{c}\text { A small number of participants and no control } \\
\text { group, children were not mature enough, potential } \\
\text { effects of other classes, heterogeneous autism } \\
\text { severity on children, unpredicted behaviors during } \\
\text { sessions, engineering and technical issues, the small } \\
\text { number of sessions. }\end{array}$ \\
\hline
\end{tabular}

The use of the NAO robot showed significant

[34] ASD improvement in several aspects of learning behaviors, confirming the confidence level

Not reported. for the techniques used.

[35] ASD Reduction in anxiety and increase in compliance with instructions.

Distrust task: the independent-sample Welch $t$-test showed a significant difference in overall distrust performance between the ASD $(\mathrm{M}=7.70, \mathrm{SD}=2.62)$ and TD groups $(\mathrm{M}$ $=9.35, \mathrm{SD}=0.67$. TD children were more

likely than children with ASD to distrust the robot who offered incorrect information. Deception task: the overall performance analysis of the deception task also found a significant difference in the overall deception performance between the ASD $(M=6.70, S D$ $=3.64)$ and $\mathrm{TD}(\mathrm{M}=9.55, \mathrm{SD}=1.19)$ groups, indicating that TD children were more likely to deceive the robot than children with ASD.

The results obtained show that children can adapt quickly to the robot, and in the case of Multiple
[37]
disabilities Helped to address the educational, cognitive, physical and social needs of the children, engaging youth with disabilities in a robotics program.
Did not use a within-subject design to compare the same participants with human and robot conditions. Although there is no significant difference in the mean ages between the two ASD groups, the age difference of six months could still represent different neurodevelopmental patterns in children, which could affect their interactions with robots and humans.

The anthropomorphic thinking for the human condition was not investigated; thus, it is not clear whether the interaction progress would affect children's anthropomorphic thinking answers. To study the regional difference of the performance of this study, and to replicate these findings in more cities and counties.

Three main improvements were identified for this study, based on its challenges: (1) to scale the research and to repeat it in more sites, (2) to increase the number of female children and (3) to generalize the designed experiments to children with other disabilities, since the authors realized that STEM learning for children with various disabilities may have different meanings and is an area worthy of further exploration. 
Table 5. Cont.

\begin{tabular}{|c|c|c|c|}
\hline Reference & Impairment & Outcomes & Challenges \\
\hline [39] & $\begin{array}{l}\text { Multiple } \\
\text { disabilities }\end{array}$ & $\begin{array}{l}\text { Children were engaged in the activity from } \\
\text { the very beginning of the session. }\end{array}$ & $\begin{array}{l}\text { The appearance and behaviors did not evoke an } \\
\text { agent with its inner state and intentionality. Issues } \\
\text { are mainly related to the functional aspect of the } \\
\text { visual interface, design of the physical appearance of } \\
\text { the robot and its faces. }\end{array}$ \\
\hline$[40]$ & $\begin{array}{l}\text { Multiple } \\
\text { disabilities }\end{array}$ & $\begin{array}{l}\text { Helped to address the educational, cognitive, } \\
\text { physical and social needs of the children. }\end{array}$ & $\begin{array}{l}\text { The research was conducted at only one site. The } \\
\text { girls were under-represented in the program. }\end{array}$ \\
\hline [41] & $\begin{array}{l}\text { Multiple } \\
\text { disabilities }\end{array}$ & $\begin{array}{l}\text { "No response" count decreases and flattens } \\
\text { out with improvement. The "correct } \\
\text { response" count consistently increases. These } \\
\text { counts are consistent with the increase of } \\
\text { total directives over time. The results for } \\
\text { subject } 3 \text { are inconclusive. Another subject } \\
\text { made considerable progress according to the } \\
\text { SLP and SPED teacher. }\end{array}$ & Not reported. \\
\hline [42] & $\begin{array}{l}\text { Multiple } \\
\text { disabilities }\end{array}$ & $\begin{array}{l}\text { The Wilcoxon signed-rank test showed that } \\
\text { for the group as a whole, ratings were } \\
\text { significantly higher when working } \\
\text { with the robot. }\end{array}$ & $\begin{array}{l}\text { There was a small amount of bias that may have } \\
\text { influenced the teachers' ratings. There were more } \\
\text { people present in the classroom than when working } \\
\text { with the robot and there was also the researcher } \\
\text { and a camera. }\end{array}$ \\
\hline
\end{tabular}

No positive changes for the Sensory

[43] Multiple developmental area were recorded. The disabilities motor developmental area was the only one that did not report any negative changes.
To extend this preliminary study.

Some children had the highest increase on the variable "communication with Teo", while others had a high decrease. For four children, there was an increase in some variables, while there was a strong decrease

[44] Multiple in two children. The variable "manipulation disabilities of Teo" had a decrease for all children except

Causality relationships are hard to measure. for two of them. Additionally, the variables

"externalization of needs", "positive emotions" and "negative emotions" showed a positive trend in the second session in both groups of children.

\begin{tabular}{|c|c|c|c|}
\hline [45] & $\begin{array}{l}\text { Multiple } \\
\text { disabilities }\end{array}$ & $\begin{array}{l}\text { Improvements in distinguishing the cards } \\
\text { and overall behavior. }\end{array}$ & Not reported. \\
\hline [46] & $\begin{array}{l}\text { Multiple } \\
\text { disabilities }\end{array}$ & $\begin{array}{l}\text { The mean score of IPPA before the sessions } \\
\text { was } 11.8 \text {, and the mean score after the } \\
\text { sessions was } 8.8 \text {. }\end{array}$ & Not reported. \\
\hline [47] & $\begin{array}{l}\text { Multiple } \\
\text { disabilities }\end{array}$ & $\begin{array}{l}\text { Analysis of the data from the pre- and } \\
\text { post-test questionnaires; all items were } \\
\text { compared with each other in order to } \\
\text { evaluate possible improvements in the } \\
\text { developmental target areas. }\end{array}$ & $\begin{array}{c}\text { The ability to speak and understand the language } \\
\text { was vital for the children. Study data are } \\
\text { preliminary. }\end{array}$ \\
\hline [48] & $\begin{array}{l}\text { Multiple } \\
\text { disabilities }\end{array}$ & $\begin{array}{l}\text { The three students became more confident } \\
\text { and willing to engage in conversation after } \\
\text { interacting with the robot over a } \\
\text { period of time. }\end{array}$ & Not reported. \\
\hline [49] & $\begin{array}{c}\text { Multiple } \\
\text { disabilities }\end{array}$ & $\begin{array}{l}\text { They confirmed the lasting positive change } \\
\text { by gross observation. }\end{array}$ & $\begin{array}{l}\text { One boy did not like the big eyes or the slight } \\
\text { drive noise. }\end{array}$ \\
\hline
\end{tabular}


Table 5. Cont.

\begin{tabular}{cccc}
\hline Reference & Impairment & Outcomes & Challenges \\
\hline & $\begin{array}{c}\text { All groups in this experiment improved their } \\
\text { knowledge and skills between the pre-test } \\
\text { and the post-test. The interaction with the } \\
\text { robot was more efficient in improving } \\
\text { functional knowledge and skills. Students' } \\
\text { IQQ levels showed an improvement. }\end{array}$ & Not reported. \\
& disabilities & &
\end{tabular}

Children successful at the end of the therapy. Two children with profound ID did not

[51] Multiple benefit from robot-assisted therapy. All children increased the time spent

The results of this study only indicate the underlying potential of research in this field. imitating the robot.

\begin{tabular}{|c|c|c|c|}
\hline [56] & $\begin{array}{l}\text { Cerebral } \\
\text { palsy }\end{array}$ & $\begin{array}{l}\text { All children liked the sessions with the } \\
\text { Rehabilitation Robot. The children wanted } \\
\text { him to be present during their other sessions. }\end{array}$ & Not reported. \\
\hline [57] & $\begin{array}{l}\text { Cerebral } \\
\text { palsy }\end{array}$ & $\begin{array}{l}\text { The robot misinterprets children with the } \\
\text { speech impediment. }\end{array}$ & Not reported. \\
\hline [59] & $\begin{array}{l}\text { Cerebral } \\
\text { palsy }\end{array}$ & $\begin{array}{l}\text { Scoring based on Rasch analysis. During } \\
\text { intervention, all children had an increase in } \\
\text { self-control, specifically the items decides, } \\
\text { modifies, initiates and transitions. }\end{array}$ & $\begin{array}{c}\text { The Lego Invention robot is not } 100 \% \text { accurate } \\
\text { in its movements. }\end{array}$ \\
\hline [60] & ADHD & $\begin{array}{l}\text { Learning time (min:sec): without robot: } \\
\text { 15:28, } 12: 49 ; \\
\text { with robot: } 18: 05,13: 45 \text {. } \\
\text { Running time: without robot: } 6 \text { and } 5 \text { times; } \\
\text { with robot: } 7 \text { and } 9 \text { times. }\end{array}$ & Not reported. \\
\hline [62] & $\begin{array}{l}\text { Hearing im- } \\
\text { pairments }\end{array}$ & $\begin{array}{l}\text { The children of beginner's level preferred to } \\
\text { play with NAO first. Their average error } \\
\text { rates are smaller in the games played with R3 } \\
\text { than NAO in the first games, and total error } \\
\text { in both games. }\end{array}$ & $\begin{array}{c}\text { The robots, due to their hands, did not correctly sign } \\
\text { one of the words. }\end{array}$ \\
\hline [64] & $\begin{array}{l}\text { Down } \\
\text { syndrome }\end{array}$ & $\begin{array}{l}\text { Participants had a higher percentage of } \\
\text { engagement with the Lego Mindstorm than } \\
\text { with the NAO. In the fourth participant, } \\
\text { there was no difference in percentage } \\
\text { engagement between the two robots. In } \\
\text { terms of percentage errors, there was no } \\
\text { difference between the two robots in } \\
\text { all four participants. }\end{array}$ & $\begin{array}{l}\text { The learning objectives were limited to those that } \\
\text { could be carried out with both robots. }\end{array}$ \\
\hline [65] & $\begin{array}{l}\text { Down } \\
\text { syndrome }\end{array}$ & $\begin{array}{l}\text { The child was more interactive with the } \\
\text { experimenter and the robot during the } \\
\text { sessions with the Kaspar robot. }\end{array}$ & Not reported. \\
\hline [68] & $\begin{array}{l}\text { Oncological } \\
\text { disorders }\end{array}$ & $\begin{array}{l}\text { The motivation was assessed using three } \\
\text { measures based on the Fun Toolkit. }\end{array}$ & Not reported. \\
\hline
\end{tabular}

\section{Robots-Taxonomy}

An in-depth study of the published research efforts to integrate social robots into special education has highlighted the wide variety of social robots that have been developed and tested in a highly diverse set of experiments with children with various impairments. The need for the most useful social robots has led the market to design and produce a wide range of social robots with varying features (Tables 6 and 7). Among other things, this has highlighted the need for a customized methodology for developing [71] and selecting [72] social robots for specific applications. 
In this section, an attempt is made to record the various types of social robots that have been applied in special education, with the ultimate goal of concluding the suitability of each type of robot for each category of impairments.

\subsection{NAO Robot}

A significant number $(46 \%, \mathrm{~N}=47)$ of studies used the NAO robot and it seems that in almost all the cases, NAO was used to help children with ASD. In other examples, it was also used to help children with multiple disabilities (from which most cases were with at least one of the disabilities being ASD), intellectual disabilities, Down syndrome, cerebral palsy, oncological disorders, physical disabilities and hearing impairments. In most cases, a humanoid robot is required as during the interaction between the robot and the child, the child had to imitate the robot's movements to improve its joint attention skills, mobility, or carry out other kinds of body exercises. This makes the choice of NAO robot more suitable as the movements can be programmed easily, with the help of its desktop program and its degrees of freedom to move. In addition to movement exercises, it was also used in cases of learning sessions and social interactions, where the children interacted by talking to each other.

\subsection{Kaspar Robot}

Kaspar, the second most popular social root $(6 \%, \mathrm{~N}=6)$, was used in studies that focused on children with ASD, Down syndrome and multiple disabilities (from which one was also ASD). Kaspar's humanoid body and features seem to help more children with ASD. In some of the studies, Kaspar was used with the intention of exploring and measuring its potentials in the improvement of children's general behavior by playing games and participating in play scenarios.

\subsection{Lego Mindstorms}

Different kinds of robots can be built with the Lego Mindstorms (the third most popular social root, used in five studies ( $4.85 \%)$ used this kind of robot) set. In most cases, the particular set was used to build robots that were applied to studies with children with diverse disabilities, such as ASD, multiple disabilities, cerebral palsy, Down syndrome, developmental disorder and other movement disabilities. Due to its design, the robot can be either a non-humanoid (a vehicle) or a humanoid robot. The interactions of the studies that this robot was used in vary. In some studies, the robot was used in training, learning, or working sessions, workshops and play sessions. This indicates that the robot, or the building set in general, can be used to build a robot for different kinds of interactions. In addition to that, a study conducted workshops with the particular set, in which the children had to build a robot using the set. As a result, children with movement impairments were also able to improve their mobility by building a robot with the help of other teachers participating.

In all cases, the robot was the main interaction of the child, with the exception of one, in which it was supporting the learning of the child; in other cases, the child was not alone during the interaction, with the researcher being present, or in one case, where the child was accommodated with their mother.

\section{4. iRobiQ Robot}

The iRobiQ robot was used in studies including children with ASD (or in one case, PDD-NOS). It seems that the design of the robot is mostly targeted to children with ASD impairment and the robot itself to be used in the context of interactions that aim to improve the communication and syntactic skills, or other skills that are closely related to those. In most cases, the robot was used as a tool to assist the teachers during the interaction between them and the children, by providing instructions or other assistive cues to the children. Additionally, it was used [73] to teach attention, communication and social skills to children with ASD by playing a card game and providing assistance and feedback during the game. 
It is a non-humanoid robot with a display that was used to play the card game, through which it provided the feedback in combination with its head.

\subsection{Iromec Robot}

Iromec robot was mostly used in studies where the children had multiple disabilities, Down syndrome or ASD. Iromec is a non-humanoid robot with a visual interface that can show the robot's expressions and a body interface with the main purpose of driving the interaction and stimulating specific actions. For these reasons, it was mainly used in the context of interactions where the children played with the robot or participated in play scenarios/sessions.

The children that participated in these studies and interacted with the Iromec robot were younger than 11 years old. This means that this particular robot, combined with interactions that focus on games or play scenarios, is more applicable to this age.

\subsection{Alice Robot}

Alice is a humanoid robot that looks like a young girl (Table 5). Alice was used in three studies [74-76] (2.94\% of the examined publications) with children with ASD, during which it played a game with the children to improve their imitation and joint attention skills. During the interactions, the particular robot was controlled and teleoperated using a Microsoft Kinect and with Haptic PhantomOmni.

\subsection{Probo Robot}

Probo is a humanoid robot with a safe and huggable design. This robot was used only in studies [77-79] with children with ASD. Its appearance is that of a stuffed imaginary animal providing soft touch and acting as a social interface by employing social cues and communication modalities. In one case, it was used to improve the social skills of the children by participating with each child in a social story.

\subsection{KiliRo Robot}

KiliRo is a parrot robot, which was used only in studies [80,81] with children with ASD. In those studies, KiliRo was used to lower the stress levels of the children or to improve the interaction of the teacher with the child by essentially making the child more relaxed or by assisting them. This indicates that this kind of robot (zoomorphic), or at least the particular one, can be used as a relaxing tool for the children. The usual interaction is a learning activity that aimed to improve the children's learning abilities, as an assistance tool or as the main interaction media.

\subsection{Zeno Robot}

Zeno is a humanoid robot that resembles a small boy. This robot was used in two studies $[82,83]$ as a social mediator and as an assistant in game scenarios with children with ASD. The main target of using this robot was to improve the eye contact, joint attention, symbolic play, and basic emotion recognition of the children.

\subsection{Miscellaneous Robots}

Aibo robot, which is a dog robot, was used in an explorative study [84] for children with ASD that aimed to check if the specific robot engaged the children more into the activities. The interactions were interactive sessions with the robot, during which the children played or interacted with the robot while the experimenter was watching them or asking some questions.

Rero is a humanoid social robot [31] used to establish a child-robot interaction based on five interaction modules designed for children with ASD. This robot is reconfigurable and can be programmed to execute various interaction scenarios. Its mobility along with the attractive appearance make this robot suitable to increase the engagement of the children during the interventions. 
Cozmo is a very cute non-humanoid robot that has the form of a small truck (Table 6). It is mainly used for children's companion and entertainment since it can be programmed to dance, sneeze, or play several games. In the study [53], adults with multiple impairments interacted with Cozmo while playing games, with the robot analyzing the behavior of the participants.

Paro is a non-humanoid (pet-like) social robot with the appearance of a baby seal. This social robot was used as a therapeutic tool in $[49,85]$ for children with multiple impairments, by improving the children's cognitive skills through game/play sessions or free interactions.

MiRo is also a non-humanoid (pet-like) social robot, which has the form of a small dog. It is autonomous and is characterized by a brain-like control system. In [35], MiRo interacted with children with ASD, which helped them to reduce their anxiety and increased their compliance with game instructions.

CommU is a humanoid robot capable of initiating and maintaining conversations with ASD-impaired children [27]. It can move its head, eyes and body to reproduce human-like expressions during the conversation.

Astro was used in one study [30] with children with ASD for therapeutic purposes and was part of larger system architecture. Astro is a non-humanoid robot that was controlled by one researcher whilst another controlled its social behavior (speech and facial expressions) during the therapeutic sessions with the children. Moreover, a restrictedperception WoZ methodology was also applied. According to the researchers, this robot was used because it can socially interact with the children and is fully autonomous during therapy sessions.

The QTrobot was used in [86] that included children with ASD. This robot is a childsized humanoid robot, with an expressive social appearance and a screen that allows the presentation of animated faces. QTrobot was used in the study as an interview partner to the child, during which it told a story, then asked some questions and lastly played an imitation game.

InMoov is a humanoid social robot designed [33] for interacting with ASD-impaired children. This is the first open-source 3D printed social robot [87], which anyone can print at home, subject to 3D printer availability. The main advantage of this robot is it is modular and adaptive nature, which permits it to be modified according to the needs of the study.

Ifbot is a non-humanoid robot able to communicate with humans verbally and nonverbally, with facial expression emotions. It is equipped with the appropriate hardware to execute computer vision algorithms such as object recognition, tracking etc. In [60], Ifbot was used to promote collaborative learning between children with ADHD.

Keepon is a non-humanoid robot that was used [88] as a tool to give feedback to children with ASD during their learning tasks with the teachers. An operator gave the feedback of the robot manually.

FACE is an android that includes the FACET, which is a complete therapy infrastructure based on the integration of the HIPOP (Human Interaction Pervasive Observation Platform). This humanoid robot, which has the appearance of a female human, interacted with children with ASD in order to improve their social capabilities through psychologistdriven interactions. During the interactions, the robot was performing expressions with its face and then the children had to label and imitate them, and at a later stage, the children were free to play and observe the robot [89].

Kinetron is a humanoid robot that was used in a study with children with cerebral palsy [56]. In this study, the robot was used in the context of games that aimed to rehabilitate the children's neurophysiology. KineTron was chosen because of its ability to perform precise movements with specified speed and force, providing feedback about position and tension and the ability to arrange complex movement patterns with the use of its special software RoboPlus.

Pleo is a socially expressive dinosaur robot that was designed to express emotions and attentions using body movement and vocalizations that are easily recognizable. It was 
used [90] to elicit social interaction and host of social perception reasoning to children with ASD, during a triadic interaction with the child and a teacher.

Queball is a robotic ball that is designed with the following feature categories: play, rough-and-tumble play, cognitive potential enhanced by movement and physical wellbeing. For these reasons, the robot was used in the study [91] as a therapeutic tool for children with ASD by engaging them in social interaction and physical, fun, learning and communication play.

Although Robovie R3 was used [62] in a part of the study, its humanoid characteristics made the children with hearing impairments better understand the signs it was showing, in comparison to the NAO robot that showed the same, during the sign language game they played. This was due to its 29 degrees of freedom and five independent fingers in its hands, combined with its expressive face.

SPELTRA (Speech and Language Therapy Robotic Assistant) was used [39] in speech exercises with children with multiple impairments. SPELTRA is a robotic system focused on providing support in speech therapy, with the main function of interacting with children through educational exercises and relational activities. It can also indirectly assist during the therapists in tasks.

Teo, a non-humanoid robot, was used [44] mainly to investigate its potential with children with ASD, Down syndrome, intellectual disabilities, Prader-Willi syndrome, psychosis and multiple disabilities. The children were left to play freely with the robot while the therapist was present.

Troy is a humanoid robot with only the upper torso, and has the size of an average four-year-old child. Troy was used [92] to examine the effects of its intervention on the challenging or tantrum behaviors of children with ASD, by letting it communicate with them.

In the following Tables 6 and 7, the appearance of some popular social robots along with their main characteristics are presented, respectively.

Table 6. Appearance of some of the most popular social robots used in special education.

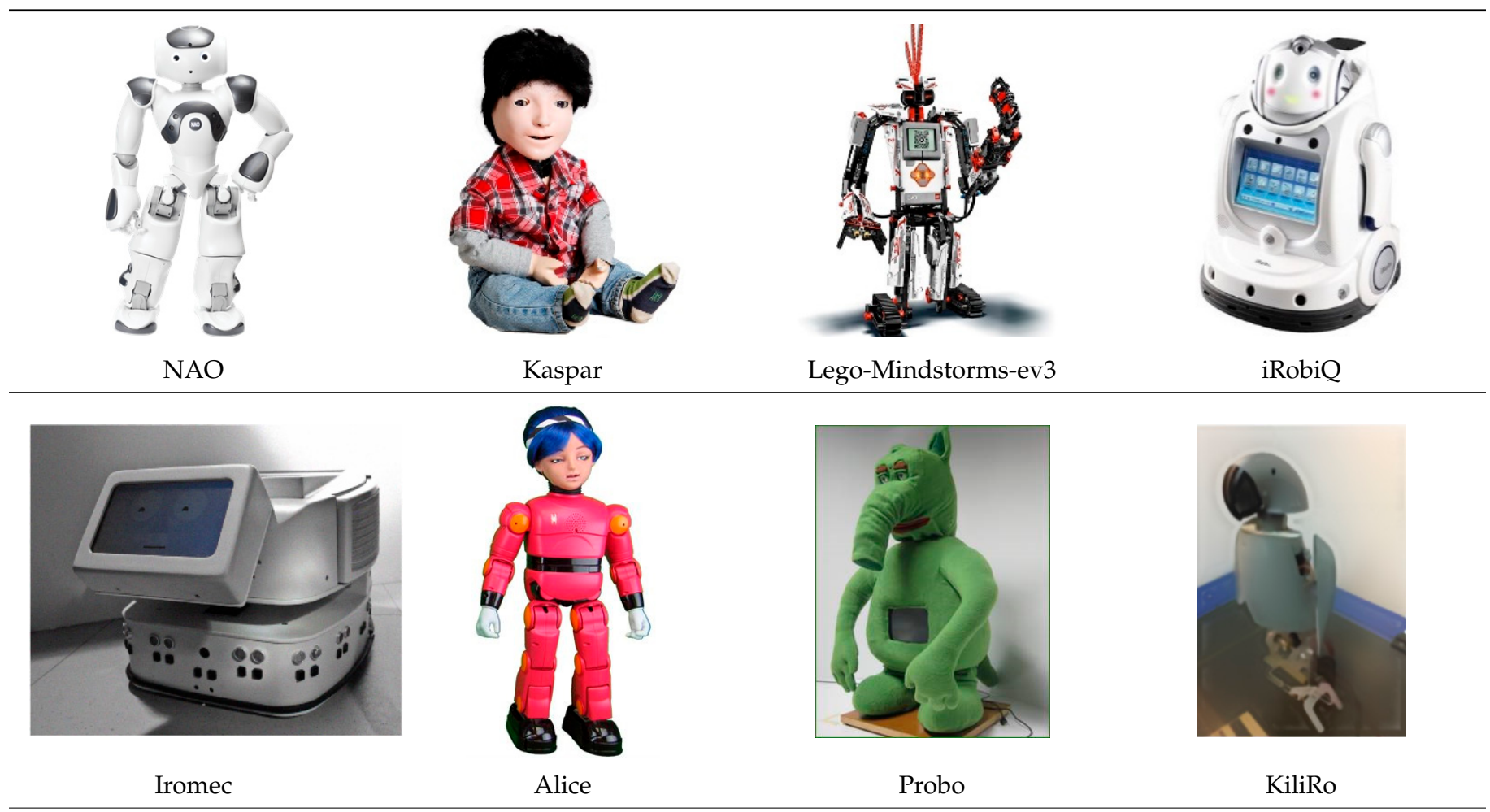


Table 6. Cont

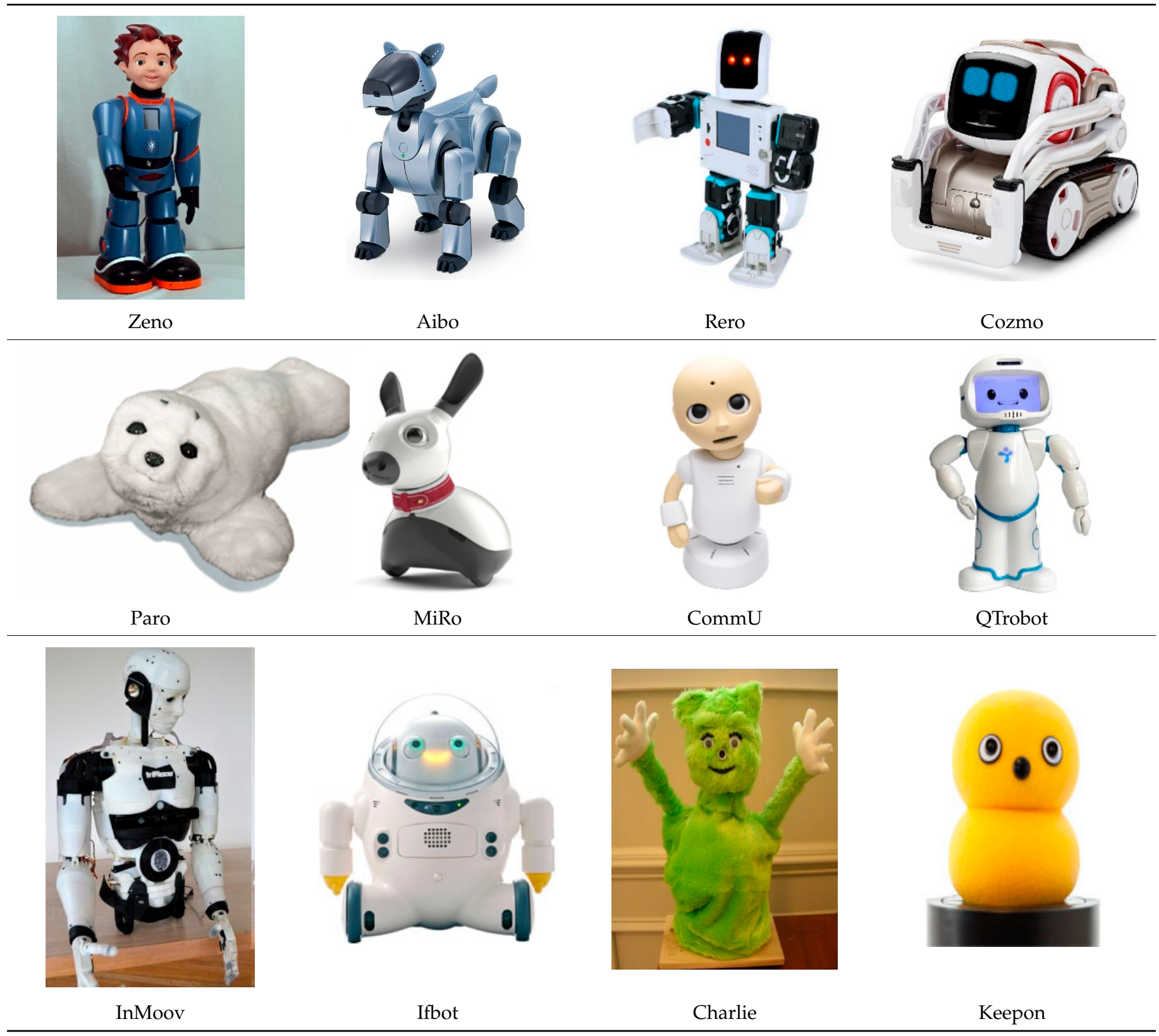

Table 7. Main characteristics of the commonly used social robots.

\begin{tabular}{|c|c|c|c|c|c|}
\hline $\begin{array}{l}\text { Robot } \\
\text { Name }\end{array}$ & Robot Type & Ref. & Impairments & Robot Role & Interaction \\
\hline NAO & Humanoid & $\begin{array}{c}{[25,26,28,29,34-} \\
36,41,42,46,48,50, \\
51,54,55,57,62,64 \\
68,75,77,85,93-109]\end{array}$ & $\begin{array}{c}\text { ASD, multiple } \\
\text { impairments, cerebral } \\
\text { palsy, hearing } \\
\text { impairments, } \\
\text { oncological disorders }\end{array}$ & $\begin{array}{l}\text { Proactive companion, } \\
\text { assistive intervention } \\
\text { tool, social mediator, } \\
\text { therapeutic assistant }\end{array}$ & $\begin{array}{l}\text { Imitation, therapeutic } \\
\text { games, free play } \\
\text { sessions, teaching joint } \\
\text { attention, } \\
\text { learning sessions }\end{array}$ \\
\hline Kaspar & Humanoid & {$[32,47,65,110-112]$} & $\begin{array}{l}\text { ASD, multiple } \\
\text { impairments, } \\
\text { Down syndrome }\end{array}$ & Game partner & $\begin{array}{c}\text { Unconstrained } \\
\text { interaction, tactile } \\
\text { interaction through } \\
\text { tactile play } \\
\text { scenarios, games }\end{array}$ \\
\hline
\end{tabular}


Table 7. Cont.

\begin{tabular}{|c|c|c|c|c|c|}
\hline $\begin{array}{l}\text { Robot } \\
\text { Name }\end{array}$ & Robot Type & Ref. & Impairments & Robot Role & Interaction \\
\hline $\begin{array}{l}\text { Lego } \\
\text { Mind- } \\
\text { storms }\end{array}$ & $\begin{array}{l}\text { Non-Humanoid } \\
\text { Humanoid }\end{array}$ & {$[37,45,59,113,113]$} & $\begin{array}{l}\text { Multiple impairments, } \\
\text { cerebral palsy }\end{array}$ & Main interaction & $\begin{array}{l}\text { Working sessions, } \\
\text { workshops (program } \\
\text { robot to solve } \\
\text { problems), games }\end{array}$ \\
\hline iRobiQ & Humanoid & {$[73,114-116]$} & $\begin{array}{l}\text { ASD, multiple } \\
\text { impairments }\end{array}$ & Main interaction & $\begin{array}{l}\text { Story intervention, } \\
\text { social interaction }\end{array}$ \\
\hline Iromec & Non-Humanoid & {$[40,43,47,65,117]$} & $\begin{array}{l}\text { ASD, multiple } \\
\text { impairments, } \\
\text { Down syndrome }\end{array}$ & $\begin{array}{l}\text { Companion and } \\
\text { teacher assistant }\end{array}$ & $\begin{array}{l}\text { Play scenarios, triadic } \\
\text { interaction, imitation }\end{array}$ \\
\hline Alice & Humanoid & [74-76] & ASD & Game partner & Game, triadic interaction \\
\hline Probo & $\begin{array}{l}\text { Humanoid } \\
\text { (pet-like) }\end{array}$ & [77-79] & ASD & Main interaction & Storytelling, game \\
\hline KiliRo & $\begin{array}{l}\text { Non-Humanoid } \\
\text { (pet-like) }\end{array}$ & {$[80,81]$} & ASD & $\begin{array}{l}\text { Lower stress levels of } \\
\text { the children, improve } \\
\text { the interaction of } \\
\text { the teacher }\end{array}$ & $\begin{array}{c}\text { Pronouncing letters and } \\
\text { dancing, free interaction, } \\
\text { learning activities }\end{array}$ \\
\hline Zeno & Humanoid & {$[82,83]$} & ASD & $\begin{array}{c}\text { Social } \\
\text { mediator, assistant }\end{array}$ & $\begin{array}{l}\text { recognize emotions in a } \\
\text { game scenario, } \\
\text { stimulus-reinforcement }\end{array}$ \\
\hline Aibo & $\begin{array}{l}\text { Non-Humanoid } \\
\text { (pet-like) }\end{array}$ & [84] & ASD & Main interaction & $\begin{array}{l}\text { Interactive and therapy } \\
\text { sessions }\end{array}$ \\
\hline Rero & Humanoid & {$[31]$} & ASD & Main interaction & Interaction modules \\
\hline Cozmo & Non-Humanoid & [53] & Multiple impairments & Main interaction & Games \\
\hline Paro & $\begin{array}{l}\text { Non-Humanoid } \\
\text { (pet-like) }\end{array}$ & {$[49,85]$} & Multiple impairments & Main interaction & Free interaction \\
\hline MiRo & $\begin{array}{l}\text { Non-Humanoid } \\
\text { (pet-like) }\end{array}$ & [35] & ASD & Main interaction & Mixed play activities \\
\hline CommU & Humanoid & [27] & ASD & Main interaction & Conversations \\
\hline Astro & Non-Humanoid & {$[30]$} & ASD & Main interaction & Therapy sessions \\
\hline QTrobot & Humanoid & [86] & ASD & Interview partner & $\begin{array}{l}\text { Storytelling, ask } \\
\text { questions, } \\
\text { imitation games }\end{array}$ \\
\hline InMoov & Humanoid & [33] & ASD & Teacher assistant & Sign language learning \\
\hline Ifbot & Non-Humanoid & {$[60]$} & ADHD & Collaborative learning & $\begin{array}{l}\text { Wizard of } \mathrm{Oz}, \\
\text { main interaction }\end{array}$ \\
\hline Keepon & $\begin{array}{l}\text { Non-humanoid } \\
\text { (pet-like) }\end{array}$ & [88] & ASD & $\begin{array}{l}\text { Gives feedback to the } \\
\text { children }\end{array}$ & $\begin{array}{l}\text { Learning/reversal } \\
\text { learning task }\end{array}$ \\
\hline FACE & $\begin{array}{l}\text { Humanoid } \\
\text { (Android) }\end{array}$ & [89] & ASD & $\begin{array}{c}\text { Treatment } \\
\text { assistive tool }\end{array}$ & Imitation games \\
\hline Kinetron & Humanoid & {$[56]$} & Cerebral palsy & $\begin{array}{l}\text { Rehabilitation, precise } \\
\text { movements with } \\
\text { specified speed } \\
\text { and force. }\end{array}$ & Games \\
\hline Pleo & $\begin{array}{l}\text { Non-humanoid } \\
\text { (pet-like) }\end{array}$ & [90] & ASD & $\begin{array}{l}\text { Elicit social interaction } \\
\text { and host of social } \\
\text { perception reasoning } \\
\text { to children }\end{array}$ & $\begin{array}{l}\text { Triadic interaction with } \\
\text { the child and a teacher }\end{array}$ \\
\hline
\end{tabular}


Table 7. Cont.

\begin{tabular}{cccccc}
\hline $\begin{array}{c}\text { Robot } \\
\text { Name }\end{array}$ & Robot Type & Ref. & Impairments & Robot Role & Interaction \\
\hline Queball & Non-humanoid & {$[91]$} & ASD & Therapeutic tool & Social interaction, play \\
\hline $\begin{array}{c}\text { Robovie } \\
\text { R3 }\end{array}$ & Humanoid & {$[62]$} & Hearing impairments & Teacher assistant & Sign language learning \\
\hline SPELTRA & Non-humanoid & {$[39]$} & Multiple impairments & Main interaction & Speech exercises \\
\hline Teo & Non-humanoid & {$[44]$} & $\begin{array}{c}\text { Multiple impairments, } \\
\text { Down syndrome }\end{array}$ & Main interaction & Free play \\
\hline Troy & Humanoid & {$[92]$} & ASD & Treatment & Social communication \\
\hline
\end{tabular}

\section{Discussion}

In the previous sections, the research attempts for the integration of social robots in the special education of children in the period 2008 to 2020 were recorded and presented in detail. The purpose of this analysis is to investigate the answers to the four questions that were initially posed as the main objectives of this systematic review.

In particular, the statistical analysis of papers published both chronologically and geographically indicates a growing research interest of the scientific community to apply social robots in the education of children and adults with impairments. Figure 3 shows Europe leading the effort to integrate social robots into special education, followed by the U.S.A. The need for the inclusion of these individuals into modern societies as equal members of them requires the acceleration of this integration world-wide. It seems that the rapid development of technology and artificial intelligence can help in this direction, through the development of more and more autonomous and intelligent social robots (Table 6).

In addition, another evidence that proves the high degree of integration of social robots in special education is the wide variety of impairments (Figure 6) of children who participated in interaction sessions with social robots. Although most of the publications are about groups of people with ASD, which was to be expected, the variety of different impairments that have been the subject of a study of the application of social robots is surprising. In all these cases, and although most studies have yielded encouraging results, it is a common finding that this road is very long.

Regarding the third question to be investigated, about the suitability of social robots in specific impairments, based on the analysis that was carried out, it appears that specific characteristics of robots are very useful for specific impairments. For example, the NAO robot, which is the most equipped robot of all, is preferred for educating children with ASD, which are cases that are more complex. In addition, in children with hearing problems, robots with five fingers are suggested for the teaching of sign language, e.g., Robovie R3, or InMoov. Apart from the type of impairment, another factor that determines the suitability of a robot is the age of the children involved. Thus, for young children, pet-like robots (Parot, Aibo, Pleo, etc.) prove to be more suitable due to their more playful appearance. However, a targeted study is required to identify the desired technical characteristics of the robots for each impairment, in order to select the most suitable robot in each case. It is worth mentioning that most robots on the market have been developed mainly for the education, entertainment and companionship of the children of typical education who are the largest population and not for the children of special education. Therefore, the design of robots aimed at children in special education is an unexplored field, in the direction of which more efforts are expected in the near future.

As far as the intelligence level of the social robots involving in special education is concerned, it is deduced that it does not differ from that of the typical education. Usually, the scientists follow the path taken by the pioneer Marvin Minsky [118], based on which several small and less intelligent parts build intelligence. In this context, face detection, face 
recognition, speech recognition, emotional recognition, visual behavioral analysis, visual tracking, etc. algorithms [119] are used to build intelligence in social robots that enable them to interact with children more naturally. However, it is worth mentioning that the needs for intelligent interaction of the robot with children in special education are particularly high, due to the particular behavior of children, e.g., in the expression of emotions. Therefore, the design of intelligent algorithms and/or the adaptation of existing algorithms to the specifics of each category of impairments is considered of paramount importance.

Although all the research papers studied in this work have reached positive conclusions about the use of social robots, in most cases, the authors have reported the challenges (Table 5) that need to be addressed in the future, because of the weaknesses of their methodologies. In conclusion, one could say that the biggest challenge that researchers have to deal with is conducting a large-scale study of the effect of social robots on special education, with large groups of children. It is worth mentioning that out of the total number of publications, the number of participants was 11.29 on average, while only six studies involved more than 20 children, with the study in [52] showing the highest number of participants equal to 74 . At the same time, there is reduced participation in the researches of females, since, on average, 2.69 females participate in the sessions compared to 8.5 males, while in $10 \%$ of cases no girls participated at all. The small number of participants in combination with the lack of a control group are often factors that reduce the statistical accuracy of the studies and the reliability of their results. In addition, due attention has not yet been paid to the long-term effect of social robots on special education, through follow-up sessions, to study the maturation factor of the effects that children have on their interaction with social robots.

Finally, another area of significant challenges is the study of the intervention methodologies proposed in the various works. In this field, there is an inconsistency between the methodologies for developing intervention scenarios, resulting in not very convincing conclusions. Future work should be directed to compare the proposed intervention methods and interaction scenarios so that the conclusions drawn are more reliable.

\section{Conclusions}

In this work, the research activity of the period 2008 to 2020 regarding the application of social robots in special education was presented systematically. The study focused on four distinct directions: (1) the investigation of the degree of integration of social robots in the training of special education individuals, (2) the assessment of the scope of application of social robots in different impairments, (3) the search for different types of social robots and their appropriateness by category of impairments and (4) the emergence of challenges that need to be addressed in order for social robots to make a significant contribution to the social integration of people with impairments.

The present study quantified the satisfactory degree of integration of social robots in special education as well as the wide range of applications of social robots in a variety of impairments. A large number of different social robots used in special education were also identified, but it was found that most of them were not designed for the specific needs of special education individuals. The challenges highlighted through this study are mainly focused on the small size of the groups of children participating in the sessions, the low participation rate of girls, the lack of control group and follow up sessions, and the finding that the design of intervention scenarios should be executed with clear objectives so that the interpretation of the results leads to safe conclusions. This set of challenges should be the subject of future research in this field, towards the use of existing knowledge for the more effective integration of social robots in special education.

Author Contributions: Conceptualization, G.A.P.; methodology, G.A.P.; investigation, G.A.P., G.K.S., C.I.P.; resources, E.V., V.-A.N., M.T.P.; data curation, G.K.S., C.I.P., E.V.; writing-original draft preparation, G.A.P., G.K.S., V.H.; writing-review and editing, G.A.P., V.G.K. and M.T.P.; visualization, N.D. and V.-A.N.; supervision, G.A.P.; project administration, G.A.P.; funding acquisition, V.G.K. and G.A.P. All authors have read and agreed to the published version of the manuscript. 
Funding: This research has been co-financed by the European Union and Greek national funds through the Operational Program Competitiveness, Entrepreneurship and Innovation, under the call RESEARCH-CREATE-INNOVATE (project code: T1EDK-00929).

Conflicts of Interest: The authors declare no conflict of interest.

\section{References}

1. Lasi, H.; Fettke, P.; Kemper, H.-G.; Feld, T.; Hoffmann, M. Industry 4.0. Bus. Inf. Syst. Eng. 2014, 6, 239-242. [CrossRef]

2. Fukuyama, M. Society 5.0: Aiming for a new human-centered society. Jpn. Spotlight 2018, 27, 47-50.

3. Breazeal, C. Toward sociable robots. Robot. Autonom. Syst. 2003, 42, 167-175. [CrossRef]

4. Lin, C.-Y.; Cheng, L.-C.; Huang, C.-C.; Chuang, L.-W.; Teng, W.-C.; Kuo, C.-H.; Gu, H.-Y.; Chung, K.-L.; Fahn, C.-S. Versatile humanoid robots for theatrical performances. Int. J. Adv. Robot. Syst. 2013, 10, 7. [CrossRef]

5. Katevas, K.; Healey, P.G.; Harris, M.T. Robot comedy lab: Experimenting with the social dynamics of live performance. Front. Psychol. 2015, 6, 1253. [CrossRef] [PubMed]

6. Lytridis, C.; Bazinas, C.; Kaburlasos, V.G.; Vassileva-Aleksandrova, V.; Youssfi, M.; Mestari, M.; Ferelis, V.; Jaki, A. Social robots as cyber-physical actors in entertainment and education. In Proceedings of the 2019 International Conference on Software, Telecommunications and Computer Networks (SoftCOM), Split, Croatia, 19-21 September 2019; pp. 1-6.

7. Fazekas, G.; Horvath, M.; Toth, A. A novel robot training system designed to supplement upper limb physiotherapy of patients with spastic hemiparesis. Int. J. Rehab. Res. 2006, 29, 251-254. [CrossRef]

8. Kachouie, R.; Sedighadeli, S.; Khosla, R.; Chu, M.-T. Socially assistive robots in elderly care: A mixed-method systematic literature review. Int. J. Hum. Comput. Interact. 2014, 30, 369-393. [CrossRef]

9. Savela, N.; Turja, T.; Oksanen, A. Social acceptance of robots in different occupational fields: A systematic literature review. Int. J. Soc. Robot. 2018, 10, 493-502. [CrossRef]

10. Lytridis, C.; Bazinas, C.; Sidiropoulos, G.; Papakostas, G.A.; Kaburlasos, V.G.; Nikopoulou, V.-A.; Holeva, V.; Evangeliou, A. Distance special education delivery by social robots. Electronics 2020, 9, 1034. [CrossRef]

11. Belpaeme, T.; Kennedy, J.; Ramachandran, A.; Scassellati, B.; Tanaka, F. Social robots for education: A review. Sci. Robot. 2018, 3, eaat5954. [CrossRef]

12. Kostova, S.; Dimitrova, M.; Kaburlasos, V.; Vrochidou, E.; Papakostas, G.; Pachidis, T.; Saeva, S.; Bonković, M.; Kružić, S.; Marasović, T.; et al. Identifying needs of robotic and technological solutions for the classroom. In Proceedings of the 201826 th International Conference on Software, Telecommunications and Computer Networks (SoftCOM), Split, Croatia, 13-15 September 2018; pp. 1-6.

13. Musić, J.; Bonković, M.; Kružić, S.; Marasović, T.; Papić, V.; Kostova, S.; Dimitrova, M.; Saeva, S.; Zamfirov, M.; Kaburlasos, V.; et al. Robotics and information technologies in education: Four countries from Alpe-Adria-Danube region survey. Int. J. Technol. Des. Educ. 2020. [CrossRef]

14. Lytridis, C.; Bazinas, C.; Papakostas, G.A.; Kaburlasos, V. On measuring engagement level during child-robot interaction in education. In Proceedings of the Robotics in Education, Online. 30 September-3 October 2020.

15. Sidiropoulos, G.K.; Papakostas, G.A.; Lytridis, C.; Bazinas, C.; Kaburlasos, V.G.; Kourampa, E.; Karageorgiou, E. Measuring engagement level in child-robot interaction using machine learning based data analysis. In Proceedings of the 2020 International Conference on Data Analytics for Business and Industry: Way Towards a Sustainable Economy (ICDABI), Online. 26-27 October 2020; pp. 1-5.

16. Sano, A.; Hernandez, J.; Deprey, J.; Eckhardt, M.; Goodwin, M.S.; Picard, R.W. Multimodal annotation tool for challenging behaviors in people with autism spectrum disorders. In Proceedings of the ACM Conference on Ubiquitous Computing; Association for Computing Machinery, New York, NY, USA, 21-26 September 2012; pp. 737-740.

17. Dong, W.; Lepri, B.; Cappelletti, A.; Pentland, A.S.; Pianesi, F.; Zancanaro, M. Using the influence model to recognize functional roles in meetings. In Proceedings of the 9th international Conference on Multimodal Interfaces-Association for Computing Machinery, New York, NY, USA, 9-13 November 2007; pp. 271-278.

18. Mubin, O.; Stevens, C.J.; Shahid, S.; Mahmud, A.A.; Dong, J.-J. A review of the applicability of robots in education. Technol. Educ. Learn. 2013, 1. [CrossRef]

19. Ismail, L.I.; Verhoeven, T.; Dambre, J.; Wyffels, F. Leveraging robotics research for children with autism: A review. Int. J. Soc. Robot. 2019, 11, 389-410. [CrossRef]

20. Papakostas, G.; Sidiropoulos, G.; Bella, M.; Kaburlasos, V. Social robots in special education: Current status and future challenges. Proc. JSME Annu. Conf. Robot. Mechatron. 2018, 2018, 1P1-A15. [CrossRef]

21. Kitchenham, B. Procedures for Performing Systematic Reviews; Keele University: Keele, UK, 2004; p. 33.

22. Khan, K.S. Undertaking Systematic Reviews of Research on Effectiveness CRD's Guidance for Those Carrying Out or Commissioning Reviews; NHS Centre for Reviews and Dissemination: York, UK, 2001; ISBN 978-1-900640-20-6.

23. Scopus. Available online: https:/ / www.scopus.com (accessed on 22 June 2020).

24. Maenner, M.J. Prevalence of autism spectrum disorder among children aged 8 years-Autism and developmental disabilities monitoring network, 11 Sites, United States, 2016. MMWR Surveill. Summ. 2020, 69. [CrossRef] [PubMed]

25. Taheri, A.; Meghdari, A.; Alemi, M.; Pouretemad, H. Teaching music to children with autism: A social robotics challenge. Sci. Iran. 2019, 26, 40-58. [CrossRef] 
26. Cao, H.-L.; Esteban, P.G.; Bartlett, M.; Baxter, P.; Belpaeme, T.; Billing, E.; Cai, H.; Coeckelbergh, M.; Costescu, C.; David, D.; et al. Robot-enhanced therapy: Development and validation of supervised autonomous robotic system for autism spectrum disorders therapy. IEEE Robot. Automat. Mag. 2019, 26, 49-58. [CrossRef]

27. Shimaya, J.; Yoshikawa, Y.; Kumazaki, H.; Matsumoto, Y.; Miyao, M.; Ishiguro, H. Communication support via a tele-operated robot for easier talking: Case/laboratory study of individuals with/without autism spectrum disorder. Int. J. Soc. Robot. 2019, 11, 171-184. [CrossRef]

28. Ali, S.; Mehmood, F.; Dancey, D.; Ayaz, Y.; Khan, M.J.; Naseer, N.; Amadeu, R.D.C.; Sadia, H.; Nawaz, R. An adaptive multi-robot therapy for improving joint attention and imitation of ASD children. IEEE Access 2019, 7, 81808-81825. [CrossRef]

29. Ali, S.; Mehmood, F.; Ayaz, Y.; Asgher, U.; Khan, M.J. Effect of different visual stimuli on joint attention of ASD children using NAO robot. In Proceedings of the Advances in Neuroergonomics and Cognitive Engineering, Washington, DC, USA, 24-28 July 2019; Volume 953, pp. 490-499, ISBN 978-3-030-20472-3.

30. Melo, F.S.; Sardinha, A.; Belo, D.; Couto, M.; Faria, M.; Farias, A.; Gamboa, H.; Jesus, C.; Kinarullathil, M.; Lima, P. Project INSIDE: Towards autonomous semi-unstructured human-robot social interaction in autism therapy. Artif. Intell. Med. 2019, 96, 198-216. [CrossRef] [PubMed]

31. Ishak, N.I.; Yusof, H.M.; Ramlee, M.R.H.; Sidek, S.N.; Rusli, N. Modules of interaction for ASD children using rero robot (Humanoid). In Proceedings of the 2019 7th International Conference on Mechatronics Engineering (ICOM), Putrajaya, Malaysia, 30-31 October 2019; pp. 1-6.

32. Wood, L.J.; Robins, B.; Lakatos, G.; Syrdal, D.S.; Zaraki, A.; Dautenhahn, K. Developing a protocol and experimental setup for using a humanoid robot to assist children with autism to develop visual perspective taking skills. Paladyn J. Behav. Robot. 2019, 10, 167-179. [CrossRef]

33. Axelsson, M.; Racca, M.; Weir, D.; Kyrki, V. A participatory design process of a robotic tutor of assistive sign language for children with autism. In Proceedings of the 28th IEEE International Conference on Robot and Human Interactive Communication (RO-MAN), New Delhi, India, 14-18 October 2019; pp. 1-8.

34. Qidwai, U.; Kashem, S.B.A.; Conor, O. Humanoid robot as a teacher's assistant: Helping children with autism to learn social and academic skills. J. Intell. Robot. Syst. 2020, 98, 759-770. [CrossRef]

35. Di Nuovo, A.; Bamforth, J.; Conti, D.; Sage, K.; Ibbotson, R.; Clegg, J.; Westaway, A.; Arnold, K. An explorative study on robotics for supporting children with autism spectrum disorder during clinical procedures. In Proceedings of the Companion of the 2020 ACM/IEEE International Conference on Human-Robot Interaction, Cambridge, UK, 23-26 March 2020; pp. $189-191$.

36. Zhang, Y.; Song, W.; Tan, Z.; Zhu, H.; Wang, Y.; Lam, C.M.; Weng, Y.; Hoi, S.P.; Lu, H.; Man Chan, B.S.; et al. Could social robots facilitate children with autism spectrum disorders in learning distrust and deception? Comput. Hum. Behav. 2019, 98, 140-149. [CrossRef]

37. Lindsay, S.; Hounsell, K.G. Adapting a robotics program to enhance participation and interest in STEM among children with disabilities: A pilot study. Disab. Rehab. Assist. Technol. 2017, 12, 694-704. [CrossRef]

38. LEGO Education. Available online: https:/ / education.lego.com/en-us/products (accessed on 22 June 2020).

39. Robles-Bykbaev, V.; Ochoa-Guaraca, M.; Carpio-Moreta, M.; Pulla-Sánchez, D.; Serpa-Andrade, L.; López-Nores, M.; GarcíaDuque, J. Robotic assistant for support in speech therapy for children with cerebral palsy. In Proceedings of the 2016 IEEE International Autumn Meeting on Power, Electronics and Computing (ROPEC), Zihuatanejo, Mexico, 9-11 November 2016; pp. 1-6.

40. Marti, P.; Giusti, L. A robot companion for inclusive games: A user-centred design perspective. In Proceedings of the IEEE International Conference on Robotics and Automation, Anchorage, AK, USA, 3-8 May 2010; pp. 4348-4353.

41. Lewis, L.; Charron, N.; Clamp, C.; Craig, M. Co-robot therapy to foster social skills in special need learners: Three pilot studies. In Methodologies and Intelligent Systems for Technology Enhanced Learning; Springer: Berlin/Heidelberg, Germany, 2016 ; pp. 131-139.

42. Hedgecock, J.; Standen, P.J.; Beer, C.; Brown, D.; Stewart, D.S. Evaluating the role of a humanoid robot to support learning in children with profound and multiple disabilities. J. Assist. Technol. 2014, 8, 111-123. [CrossRef]

43. Marti, P.; Iacono, I. Learning through play with a robot companion. Everyday Technol. Indep. Care 2011, 29, 526-533.

44. Bonarini, A.; Clasadonte, F.; Garzotto, F.; Gelsomini, M.; Romero, M. Playful interaction with Teo, a mobile robot for children with neurodevelopmental disorders. In Proceedings of the 7th International Conference on Software Development and Technologies for Enhancing Accessibility and Fighting Info-Exclusion-Association for Computing Machinery, Vila Real, Portugal, 1-3 December 2016; pp. 223-231.

45. Costa, S.; Santos, C.; Soares, F.; Ferreira, M.; Moreira, F. Promoting interaction amongst autistic adolescents using robots. In Proceedings of the Annual International Conference of the IEEE Engineering in Medicine and Biology, Buenos Aires, Argentina, 31 August-4 September 2010; pp. 3856-3859.

46. Van den Heuvel, R.J.; Lexis, M.A.; de Witte, L.P. Robot ZORA in rehabilitation and special education for children with severe Physical disabilities: A pilot study. Int. J. Rehab. Res. 2017, 40, 353. [CrossRef]

47. Iacono, I.; Lehmann, H.; Marti, P.; Robins, B.; Dautenhahn, K. Robots as social mediators for children with autism-A preliminary analysis comparing two different robotic platforms. In Proceedings of the IEEE International Conference on Development and Learning (ICDL), Frankfurt, Germany, 24-27 August 2011; Volume 2, pp. 1-6. 
48. Silvera-Tawil, D.; Bradford, D.; Roberts-Yates, C. Talk to me: The role of human-robot interaction in improving verbal communication skills in students with autism or intellectual disability. In Proceedings of the 27th IEEE International Symposium on Robot and Human Interactive Communication (RO-MAN), Naples, Italy, 31 August-4 September 2018; pp. 1-6.

49. Nakadoi, Y. Usefulness of animal type robot assisted therapy for autism spectrum disorder in the child and adolescent psychiatric ward. In Proceedings of the JSAI International Symposium on Artificial Intelligence; Springer: Berlin/Heidelberg, Germany, 2015; pp. 478-482.

50. Park, E.; Kwon, S.J. I can teach them: The ability of robot instructors to cognitive disabled children. J. Psychol. Educ. Res. 2016, 24, 101-114.

51. Conti, D.; Trubia, G.; Buono, S.; Di Nuovo, S.; Di Nuovo, A. Evaluation of a robot-assisted therapy for children with autism and intellectual disability. In Proceedings of the Annual Conference Towards Autonomous Robotic Systems; Springer: Berlin/Heidelberg, Germany, 2018; pp. 405-415.

52. Wan, G.; Deng, F.; Jiang, Z.; Lin, S.; Zhao, C.; Liu, B.; Chen, G.; Chen, S.; Cai, X.; Wang, H.; et al. Attention shifting during child-Robot interaction: A preliminary clinical study for children with autism spectrum disorder. Front. Inf. Technol. Electron. Eng. 2019, 20, 374-387. [CrossRef]

53. Balasuriya, S.S.; Sitbon, L.; Brereton, M.; Koplick, S. How can social robots spark collaboration and engagement among people with intellectual disability? In Proceedings of the 31st Australian Conference on Human-Computer-Interaction, Fremantle, WA, Australia, 2-5 December 2019; pp. 209-220.

54. Zhanatkyzy, A.; Telisheva, Z.; Turarova, A.; Zhexenova, Z.; Sandygulova, A. Quantitative results of robot-assisted therapy for children with autism, ADHD and delayed speech development. In Proceedings of the Companion of the 2020 ACM/IEEE International Conference on Human-Robot Interaction, Cambridge, UK, 23-26 March 2020; pp. 541-542.

55. Rakhymbayeva, N.; Seitkazina, N.; Turabayev, D.; Pak, A.; Sandygulova, A. A long-term study of robot-assisted therapy for children with severe autism and ADHD. In Proceedings of the Companion of the 2020 ACM/IEEE International Conference on Human-Robot Interaction, Cambridge, UK, 23-26 March 2020; pp. 401-402.

56. Kozyavkin, V.; Kachmar, O.; Ablikova, I. Humanoid social robots in the rehabilitation of children with cerebral palsy. In Proceedings of the 8th International Conference on Pervasive Computing Technologies for Healthcare, Oldenburg, Germany, 20-23 May 2014; pp. 430-431.

57. Rahman, R.A.A.; Hanapiah, F.A.; Basri, H.H.; Malik, N.A.; Yussof, H. Use of humanoid robot in children with cerebral palsy: The ups and downs in clinical experience. Procedia Comput. Sci. 2015, 76, 394-399. [CrossRef]

58. BIOLOID Premium Kit. Available online: https://www.generationrobots.com/en/401066-bioloid-premium-kit-robotis.html (accessed on 22 June 2020).

59. Ríos-Rincón, A.M.; Adams, K.; Magill-Evans, J.; Cook, A. Playfulness in children with limited motor abilities when using a robot. Phys. Occupat. Ther. Pediatr. 2016, 36, 232-246. [CrossRef] [PubMed]

60. Jimenez, F.; Yoshikawa, T.; Furuhashi, T.; Kanoh, M.; Nakamura, T. Effects of collaborative learning between educational-support robots and children who potential symptoms of a development disability. In Proceedings of the 2016 Joint 8th International Conference on Soft Computing and Intelligent Systems (SCIS) and 17th International Symposium on Advanced Intelligent Systems (ISIS), Sapporo, Japan, 25-28 August 2016; pp. 266-270.

61. Kato, S.; Ohshiro, S.; Itoh, H.; Kimura, K. Development of a communication robot Ifbot. In Proceedings of the IEEE International Conference on Robotics and Automation, New Orleans, LA, USA, 26 April-1 May 2004; Volume 1, pp. 697-702.

62. Özkul, A.; Köse, H.; Yorganci, R.; Ince, G. Robostar: An interaction game with humanoid robots for learning sign language. In Proceedings of the 2014 IEEE International Conference on Robotics and Biomimetics (ROBIO 2014), Bali, Indonesia, 5-10 December 2014; pp. 522-527.

63. Vstone. Available online: http://www.vstone.co.jp/english/ (accessed on 22 June 2020).

64. Aslam, S.; Standen, P.J.; Shopland, N.; Burton, A.; Brown, D. A comparison of humanoid and non-humanoid robots in supporting the learning of pupils with severe intellectual disabilities. In Proceedings of the 2016 International Conference on Interactive Technologies and Games (ITAG), Notthingham, UK, 26-27 October 2016; pp. 7-12.

65. Lehmann, H.; Iacono, I.; Dautenhahn, K.; Marti, P.; Robins, B. Robot companions for children with down syndrome: A case study. Interact. Stud. 2014, 15, 99-112. [CrossRef]

66. Kaspar the Social Robot. Available online: https:/ / www.herts.ac.uk/kaspar/the-social-robot (accessed on 22 June 2020).

67. IROMEC. Available online: https://www.roboticstoday.com/projects/iromec (accessed on 22 June 2020).

68. Meyns, P.; van der Spank, J.; Capiau, H.; De Cock, L.; Van Steirteghem, E.; Van der Looven, R.; Van Waelvelde, H. Do a humanoid robot and music increase the motivation to perform physical activity? A quasi-experimental cohort in typical developing children and preliminary findings in hospitalized children in neutropenia. Int. J. Hum. Comput. Stud. 2019, 122, 90-102. [CrossRef]

69. Nao-Zorabots. Available online: https:// zorarobotics.be/robots/nao (accessed on 22 June 2020).

70. Fisicaro, D.; Pozzi, F.; Gelsomini, M.; Garzotto, F. Engaging persons with neuro-developmental disorder with a plush social robot. In Proceedings of the 14th ACM/IEEE International Conference on Human-Robot Interaction (HRI), Daegu, Korea, 11-14 March 2019; pp. 610-611.

71. Belpaeme, T.; Vogt, P.; Van den Berghe, R.; Bergmann, K.; Göksun, T.; De Haas, M.; Kanero, J.; Kennedy, J.; Küntay, A.C.; Oudgenoeg-Paz, O. Guidelines for designing social robots as second language tutors. Int. J. Soc. Robot. 2018, 10, 325-341. [CrossRef] [PubMed] 
72. Papakostas, G.A.; Strolis, A.K.; Panagiotopoulos, F.; Aitsidis, C.N. Social robot selection: A case study in education. In Proceedings of the 26th International Conference on Software, Telecommunications and Computer Networks (SoftCOM), Supetar, Croatia, 13-15 September 2018; pp. 1-4.

73. Jordan, K.; King, M.; Hellersteth, S.; Wirén, A.; Mulligan, H. Feasibility of using a humanoid robot for enhancing attention and social skills in adolescents with autism spectrum disorder. Int. J. Rehab. Res. 2013, 36, 221-227. [CrossRef]

74. Taheri, A.R.; Alemi, M.; Meghdari, A.; Pour Etemad, H.R.; Basiri, N.M. Social robots as assistants for autism therapy in Iran: Research in progress. In Proceedings of the Second RSI/ISM International Conference on Robotics and Mechatronics (ICRoM), Tehran, Iran, 15-17 October 2014; pp. 760-766.

75. Taheri, A.; Meghdari, A.; Alemi, M.; Pouretemad, H. Human-robot interaction in autism treatment: A case study on three pairs of autistic children as twins, siblings, and classmates. Int. J. Soc. Robot. 2018, 10, 93-113. [CrossRef]

76. Ghorbandaei Pour, A.; Taheri, A.; Alemi, M.; Meghdari, A. Human-robot facial expression reciprocal interaction platform: Case studies on children with autism. Int. J. Soc. Robot. 2018, 10, 179-198. [CrossRef]

77. Pop, C.A.; Simut, R.; Pintea, S.; Saldien, J.; Rusu, A.; David, D.; Vanderfaeillie, J.; Lefeber, D.; Vanderborght, B. Can the social robot probo help children with autism to identify situation-based emotions? A series of single case experiments. Int. J. Hum. Robot. 2013, 10, 1350025. [CrossRef]

78. Simut, R.E.; Vanderfaeillie, J.; Peca, A.; Van de Perre, G.; Vanderborght, B. Children with autism spectrum disorders make a fruit salad with probo, the social robot: An interaction study. J. Autism Dev. Disord. 2016, 46, 113-126. [CrossRef] [PubMed]

79. Vanderborght, B.; Simut, R.; Saldien, J.; Pop, C.; Rusu, A.S.; Pintea, S.; Lefeber, D.; David, D.O. Using the social robot probo as a social story telling agent for children with ASD. Interact. Stud. 2012, 13, 348-372. [CrossRef]

80. Bharatharaj, J.; Huang, L.; Al-Jumaily, A.; Elara, M.R.; Krägeloh, C. Investigating the effects of robot-assisted therapy among children with autism spectrum disorder using bio-markers. In Proceedings of the IOP Conference Series: Materials Science and Engineering, Busan, Korea, 25-27 August 2017; Volume 234, pp. 1-7.

81. Bharatharaj, J.; Huang, L.; Krägeloh, C.; Elara, M.R.; Al-Jumaily, A. Social engagement of children with autism spectrum disorder in interaction with a parrot-inspired therapeutic robot. Procedia Comput. Sci. 2018, 133, 368-376. [CrossRef]

82. Palestra, G.; Varni, G.; Chetouani, M.; Esposito, F. A multimodal and multilevel system for robotics treatment of autism in children. In Proceedings of the International Workshop on Social Learning and Multimodal Interaction for Designing Artificial Agents-DAA '16; ACM Press: Tokyo, Japan, 2016; pp. 1-6.

83. Silva, V.; Soares, F.; Esteves, J.S.; Pereira, A.P. Building a hybrid approach for a game scenario using a tangible interface in human robot interaction. In Serious Games; Göbel, S., Garcia-Agundez, A., Tregel, T., Ma, M., Baalsrud Hauge, J., Oliveira, M., Marsh, T., Caserman, P., Eds.; Lecture Notes in Computer Science; Springer International Publishing: Cham, Switzerland, 2018; Volume 11243, pp. 241-247, ISBN 978-3-030-02761-2.

84. Stanton, C.M.; Kahn, P.H.; Severson, R.L.; Ruckert, J.H.; Gill, B.T. Robotic animals might aid in the social development of children with autism. In Proceedings of the 3rd ACM/IEEE International Conference on Human-Robot Interaction (HRI); ACM Press: New York, NY, USA, 2008; pp. 271-278.

85. Alhaddad, A.Y.; Javed, H.; Connor, O.; Banire, B.; Al Thani, D.; Cabibihan, J.-J. Robotic trains as an educational and therapeutic tool for autism spectrum disorder intervention. In Robotics in Education; Lepuschitz, W., Merdan, M., Koppensteiner, G., Balogh, R., Obdržálek, D., Eds.; Advances in Intelligent Systems and Computing; Springer International Publishing: Cham, Switzeralnd, 2019; Volume 829, pp. 249-262, ISBN 978-3-319-97084-4.

86. Costa, A.P.; Charpiot, L.; Lera, F.R.; Ziafati, P.; Nazarikhorram, A.; Van Der Torre, L.; Steffgen, G. More attention and less repetitive and stereotyped behaviors using a robot with children with autism. In Proceedings of the 27th IEEE International Symposium on Robot and Human Interactive Communication (RO-MAN), Nanjing, China, 27-31 August 2018; pp. 534-539.

87. InMoov-Open-Source 3D Printed Life-Size Robot. Available online: https://inmoov.fr/ (accessed on 28 April 2021).

88. Costescu, C.A.; Vanderborght, B.; David, D.O. Reversal learning task in children with autism spectrum disorder: A robot-based approach. J. Autism Dev. Disord. 2015, 45, 3715-3725. [CrossRef]

89. Mazzei, D.; Greco, A.; Lazzeri, N.; Zaraki, A.; Lanatà, A.; Igliozzi, R.; Mancini, A.; Stoppa, F.; Scilingo, E.P.; Muratori, F. Robotic social therapy on children with autism: Preliminary evaluation through multi-parametric analysis. In Proceedings of the International Conference on Privacy, Security, Risk and Trust and 2012 International Confernece on Social Computing, Amsterdam, The Netherlands, 3-5 September 2012; pp. 766-771.

90. Kim, E.S.; Berkovits, L.D.; Bernier, E.P.; Leyzberg, D.; Shic, F.; Paul, R.; Scassellati, B. Social robots as embedded reinforcers of social behavior in children with autism. J. Autism Dev. Disord. 2013, 43, 1038-1049. [CrossRef]

91. Salter, T.; Davey, N.; Michaud, F. Designing \& developing QueBall, a robotic device for autism therapy. In Proceedings of the 23rd IEEE International Symposium on Robot and Human Interactive Communication, Edinburgh, UK, 25-29 September 2014; pp. 574-579.

92. Whitmer, T. Incorporating a Robot in Intervention with Children with ASD: The Effect on Tantrum Behaviors. Master's Thesis, Brigham Young University, Provo, UT, USA, 2015.

93. Srinivasan, S.M.; Kaur, M.; Park, I.K.; Gifford, T.D.; Marsh, K.L.; Bhat, A.N. The effects of rhythm and robotic interventions on the imitation/praxis, interpersonal synchrony, and motor performance of children with autism spectrum disorder (ASD): A pilot randomized controlled trial. Autism Res. Treat. 2015, 2015, 1-18. [CrossRef] [PubMed] 
94. So, W.-C.; Wong, M.K.-Y.; Lam, C.K.-Y.; Lam, W.-Y.; Chui, A.T.-F.; Lee, T.-L.; Ng, H.-M.; Chan, C.-H.; Fok, D.C.-W. Using a social robot to teach gestural recognition and production in children with autism spectrum disorders. Disabil. Rehab. Assist. Technol. 2018, 13, 527-539. [CrossRef]

95. Hirokawa, M.; Funahashi, A.; Itoh, Y.; Suzuki, K. Adaptive behavior acquisition of a robot based on affective feedback and improvised teleoperation. IEEE Trans. Cogn. Dev. Syst. 2019, 11, 405-413. [CrossRef]

96. Mavadati, S.M.; Feng, H.; Salvador, M.; Silver, S.; Gutierrez, A.; Mahoor, M.H. Robot-based therapeutic protocol for training children with autism. In Proceedings of the 25th IEEE International Symposium on Robot and Human Interactive Communication (RO-MAN), New York, NY, USA, 26-31 August 2016; pp. 855-860.

97. Nie, G.; Zheng, Z.; Johnson, J.; Swanson, A.R.; Weitlauf, A.S.; Warren, Z.E.; Sarkar, N. Predicting response to joint attention performance in human-human interaction based on human-robot interaction for young children with autism spectrum disorder. In Proceedings of the 27th IEEE International Symposium on Robot and Human Interactive Communication (RO-MAN), Nanjing, China, 31 August-4 September 2018; pp. 1-4.

98. Shamsuddin, S.; Yussof, H.; Ismail, L.I.; Mohamed, S.; Hanapiah, F.A.; Zahari, N.I. Initial response in HRI-A case study on evaluation of child with autism spectrum disorders interacting with a humanoid Robot NAO. Procedia Eng. 2012, 41, 1448-1455. [CrossRef]

99. Manner, M.D. Identifying differences in social responsiveness among preschoolers interacting with or watching social robots. In Proceedings of the Twenty-Seventh International Joint Conference on Artificial Intelligence-International Joint Conferences on Artificial Intelligence Organization, Stockholm, Sweden, 13-19 July 2018; pp. 5777-5778.

100. Shamsuddin, S.; Yussof, H.; Ismail, L.I.; Mohamed, S.; Hanapiah, F.A.; Zahari, N.I. Humanoid robot NAO interacting with autistic children of moderately impaired intelligence to augment communication skills. Procedia Eng. 2012, 41, 1533-1538. [CrossRef]

101. Shamsuddin, S.; Yussof, H.; Miskam, A.; Hamid, M.A.C.; Malik, N.A.; Hashim, H.; Hanapiah, A.; Ismail, L.I. Humanoid robot NAO as HRI mediator to teach emotions using game-centered approach for children with autism. In Proceedings of the HRI 2013 Workshop on Applications for Emotional Robots, Tokyo, Japan, 3-6 March 2013.

102. Anzalone, S.M.; Tilmont, E.; Boucenna, S.; Xavier, J.; Jouen, A.-L.; Bodeau, N.; Maharatna, K.; Chetouani, M.; Cohen, D. How children with autism spectrum disorder behave and explore the 4-dimensional (spatial 3D+time) environment during a joint attention induction task with a robot. Res. Autism Spect. Disord. 2014, 8, 814-826. [CrossRef]

103. Greczek, J.; Kaszubski, E.; Atrash, A.; Mataric, M. Graded cueing feedback in robot-mediated imitation practice for children with autism spectrum disorders. In Proceedings of the 23rd IEEE International Symposium on Robot and Human Interactive Communication, Edinburgh, UK, 25-29 August 2014; pp. 561-566.

104. Desideri, L. Exploring the use of a humanoid robot to engage children with Autism Spectrum Disorder (ASD). Harness. Power Technol. Improve Lives 2017. [CrossRef]

105. Alemi, M.; Basiri, N.M. Exploring social robots as a tool for special education to teach english to Iranian kids with autism. Int. J. Robot. Theory Appl. 2016, 4, 12.

106. Zheng, Z.; Zhao, H.; Swanson, A.R.; Weitlauf, A.S.; Warren, Z.E.; Sarkar, N. Design, development, and evaluation of a noninvasive autonomous robot-mediated joint attention intervention system for young children with ASD. IEEE Trans. Hum. Mach. Syst. 2018, 48, 125-135. [CrossRef] [PubMed]

107. Kaboski, J.R.; Diehl, J.J.; Beriont, J.; Crowell, C.R.; Villano, M.; Wier, K.; Tang, K. Brief report: A pilot summer robotics camp to reduce social anxiety and improve social/vocational skills in adolescents with ASD. J. Autism Dev. Disord. 2015, 45, 3862-3869. [CrossRef] [PubMed]

108. Warren, Z.E.; Zheng, Z.; Swanson, A.R.; Bekele, E.; Zhang, L.; Crittendon, J.A.; Weitlauf, A.F.; Sarkar, N. Can robotic interaction improve joint attention skills? J. Autism Dev. Disord. 2015, 45, 3726-3734. [CrossRef]

109. Anzalone, S.M.; Tanet, A.; Pallanca, O.; Cohen, D.; Chetouani, M. A Humanoid robot controlled by neurofeedback to reinforce attention in autism spectrum disorder. In Proceedings of the 3rd Italian Workshop on Artificial Intelligence and Robotics, Genova, Italy, 28-30 November 2016.

110. Wainer, J.; Dautenhahn, K.; Robins, B.; Amirabdollahian, F. Collaborating with kaspar: Using an autonomous humanoid robot to foster cooperative dyadic play among children with autism. In Proceedings of the 10th IEEE-RAS International Conference on Humanoid Robots, Nashville, TN, USA, 6-8 December 2010; pp. 631-638.

111. Wood, L.J.; Robins, B.; Lakatos, G.; Syrdal, D.S.; Zaraki, A.; Dautenhahn, K. Piloting scenarios for children with autism to learn about visual perspective taking. In Towards Autonomous Robotic Systems; Giuliani, M., Assaf, T., Giannaccini, M.E., Eds.; Lecture Notes in Computer Science; Springer International Publishing: Cham, Switzerland, 2018; Volume 10965, pp. 260-270, ISBN 978-3-319-96727-1.

112. Robins, B.; Amirabdollahian, F.; Ji, Z.; Dautenhahn, K. Tactile interaction with a humanoid robot for children with autism: A case study analysis involving user requirements and results of an initial implementation. In Proceedings of the 19th International Symposium in Robot and Human Interactive Communication, Viareggio, Italy, 12-15 September 2010; pp. 704-711.

113. Conti, D.; Di Nuovo, A.; Trubia, G.; Buono, S.; Di Nuovo, S. Adapting robot-assisted therapy of children with autism and different levels of intellectual disability: A preliminary study. In Proceedings of the Companion of the 2018 ACM/IEEE International Conference on Human-Robot Interaction, Chicago, IL, USA, 5-8 March 2018; pp. 91-92. 
114. Yun, S.-S.; Park, S.-K.; Choi, J. A robotic treatment approach to promote social interaction skills for children with autism spectrum disorders. In Proceedings of the 23rd IEEE International Symposium on Robot and Human Interactive Communication, Edinburgh, UK, 25-29 August 2014; pp. 130-134.

115. Han, B.Y.; Yim, D.; Kim, Y.T.; Lee, S.J.; Hong, K.H. The effect of a story intervention on the syntactic skills of children with autism spectrum disorders by using an educational humanoid robot. Commun. Sci. Disord. 2016, 21, 244-261. [CrossRef]

116. Jeon, K.H.; Yeon, S.J.; Kim, Y.T.; Song, S.; Kim, J. Robot-based augmentative and alternative communication for nonverbal children with communication disorders. In Proceedings of the ACM International Joint Conference on Pervasive and Ubiquitous Computing-UbiComp '14 Adjunct, Seattle, WA, USA, 13-17 September 2014; pp. 853-859.

117. Pennazio, V. Social robotics to help children with autism in their interactions through imitation. Res. Educ. Media 2017, 9, 10-16. [CrossRef]

118. Minsky, M. Society of Mind; Simon and Schuster: New York, NY, USA, 1988; ISBN 978-0-671-65713-0.

119. Sidiropoulos, G.K.; Bazinas, C.; Lytridis, C.; Papakostas, G.A.; Kaburlasos, V.G.; Kechayas, P.; Kourampa, E.; Katsi, S.R.; Karatsioras, C. Synergy of intelligent algorithms for efficient child-robot interaction in special education: A feasibility study. In Proceedings of the Robotics in Education, Online. 30 September-3 October 2020; pp. 98-105. 